\title{
Technology-based reading intervention programs for elementary grades: An analytical review
}

\author{
Hossein Jamshidifarsani ${ }^{\mathrm{a}, *}$, Samir Garbaya ${ }^{\mathrm{b}}$, Theodore Lim ${ }^{\mathrm{c}}$, Pierre Blazevic ${ }^{\mathrm{a}}$, \\ James M. Ritchie ${ }^{c}$ \\ ${ }^{a}$ END-ICAP Laboratory - INSERM, University of Versailles Saint-Quentin-en-Yvelines - Paris-Saclay, France \\ ${ }^{\mathrm{b}}$ END-ICAP Laboratory - INSERM, ENSAM, Arts et Métiers ParisTech, France \\ ${ }^{\mathrm{c}}$ School of Engineering \& Physical Sciences, Heriot-Watt University, United Kingdom
}

\section{A R T I C L E I N F O}

\section{Keywords:}

Interactive learning environments

Evaluation of CAL systems

Elementary education

Human-computer interface

Media in education

\begin{abstract}
A B S T R A C T
In modern societies, the role of reading is becoming increasingly crucial. Hence, any impairment to the reading ability can seriously limit a person's aspirations. The enormous importance of reading as an essential skill in modern life has encouraged many researchers to try and find more effective intervention approaches. Technology has been used extensively to assist and enhance literacy learning. This analytical review aims at presenting a comprehensive overview of the existing research on technology-based or technology-assisted reading interventions for elementary grades, between 2000 and 2017, along with analyzing various aspects of these studies. After extensive research, 42 articles have met the inclusion criteria, which have evaluated a total of 32 reading programs. The studies are classified into six categories of phonological awareness, phonics, vocabulary, comprehension, fluency, and multi-component. Each reading category begins with a brief introduction. Then, the content and instructional mechanisms of each program in the category is explained, alongside the outcome of its interventions. It is found that vocabulary interventions, as well as using mobile, tablet and other non-computer technologies are massively overlooked. Furthermore, a very limited number of programs focused on fluency, none of them addressed all its components. In addition, despite the required long-term practice for fostering fluency, the reviewed studies have an average intervention time shorter than other intervention categories. This paper provides researchers and solution developers with an extensive and informative review of the current state of the art in reading interventions. Additionally, it identifies the current knowledge gaps and defines future research directions to develop effective reading programs.
\end{abstract}

\section{Introduction}

Reading is the essence of academic life, and its importance can hardly be overestimated (Blomert \& Froyen, 2010). Its impairment can cause a life-long disability that affects the quality of life in numerous ways. However, reading is a complex and multifaceted process and can be challenging for some individuals to master (Valencia, 1990). Despite all of the attempts to raise the standards of reading instruction over the years, still many students fail to achieve the grade level reading when they reach the upper elementary grades, and

\footnotetext{
* Corresponding author.

E-mail addresses: hossein.jamshidifarsani@uvsq.fr (H. Jamshidifarsani), samir.garbaya@ensam.eu (S. Garbaya), t.lim@hw.ac.uk (T. Lim), pierre.blazevic@uvsq.fr (P. Blazevic), j.m.ritchie@hw.ac.uk (J.M. Ritchie).
} 
this achievement gap tends to widen during the following grades (National Governors Association, 2010; Toste \& Ciullo, 2017). The report from National Assessment of Educational Progress (2015) shows that $64 \%$ of fourth graders and 66\% of eighth graders read below their grade level, and the case for children with learning disabilities is much worse (88\% Grade 4 and $92 \%$ Grade 8 ).

The National Reading Panel (2000) has identified five core components essential for a comprehensive reading program, consisting of phonological awareness, phonics, vocabulary, comprehension, and fluency. However, the conventional methods of instructing these components are truly time-consuming, and to be effective, they need to be carried out intensively and explicitly by the instructor (Vaughn et al., 2003). Some studies have pointed out that for treating dyslexia, the instruction duration should be between 80 and $100 \mathrm{~h}$, while their healthy peers need 30-60 h (Lyytinen, Erskine, Aro, \& Richardson, 2008, pp. 454-474). Furthermore, the growing public awareness of learning disabilities and governments' inclusion policies of disabled learners on the one hand and the emergence of new ubiquitous technologies on the other hand, have encouraged many researchers to investigate and propose innovative, more engaging and more effective approaches for facilitating the literacy acquisition of young learning disabled children (Kennedy \& Deshler, 2010; Scior, 2011).

Incorporating technology into instructional intervention can have several benefits. First of all, by learning in a playful and engaging digital environment, it can increase the motivation, which can lead to the enhancement of acceptance, concentration and also the persistence in carrying out the learning tasks (Malouf, 1988; Papastergiou, 2009). The second benefit can be the capacity of technologybased instructions in reducing the cognitive load, as well as increasing the retention of the learning material (Mayer \& Moreno, 2010; T. C.; Williams \& Zahed, 1996; Ricci, Salas, \& Cannon-bowers, 1996). Third, it can provide personalized and adaptive tutoring with no or reduced involvement of instructor, which is truly beneficial when there is not enough human resource available (Andreev, Terzieva, \& Kademova-Katzarova, 2009; Athanaselis, Bakamidis, Dologlou, Argyriou, \& Symvonis, 2014). Finally, without the time limitation of an instructor, it can allow the users to reach mastery levels by letting them train at their own pace (Corbett, 2001).

There are some studies in the literature that tried to review the technology-assisted approaches in teaching literacy. MacArthur, Ferretti, Okolo, and Cavalier (2001) wrote a critical review of 14 studies applying technology to literacy instruction for school-age students with literacy problems, from 1985 to 2000. Blok, Oostdam, Otter, and Overmaat (2002) reviewed 42 studies of computerassisted reading instruction for early literacy learners, from 1990 to 2000 . Cheung and Slavin (2011) provided a meta-analysis of the effectiveness of k-12 educational technology on reading achievement, using 85 studies published during 1970-2010. Grant et al (2012) assessed the content and quality of 30 commercially available reading software for preschool, kindergarten and first grade. Edwards Santoro and Bishop (2010) evaluated 21 popular beginning reading software targeting pre-kindergarten to third grade, based on their interface design, instructional design, and content. Cidrim and Madeiro (2017) reviewed 21 studies that applied information and communication technology (ICT) to dyslexia, from 2010 to 2015.

This study is dedicated to the technology-based intervention programs for reading instruction of elementary grades. The purpose of this paper is to (1) provide a comprehensive review of studies who applied technology to their reading intervention, from 2000 to 2017 , (2) introduce briefly the reading components of phonological awareness, phonics, comprehension, fluency and vocabulary, as well as their common instructional approaches, (3) describe the content and instructional mechanisms of the identified programs, in order to provide a basis for researchers and developers new to this field, (4) analyze reviewed studies from various aspects. Forty-two studies have met the inclusion criteria, and through these studies, 32 technology-based reading programs have been identified. This paper is structured as follows. Section 2 describes the methodology used to create this review paper. A brief introduction of each reading component, and description of intervention programs addressing that reading component, as well as the details and characteristics of the reviewed studies, are brought in Section 3. Moreover, an analytical view is discussed in Section 4. A conclusion highlighting new research direction is presented in Section 5.

\section{Method}

This section is dedicated to the methodology of preparing this review paper. First, the procedure of the literature research will be outlined, then the inclusion criteria will be presented, and finally, the coding procedure used for the reviewed articles will be discussed.

\subsection{Literature research procedure}

This research was conducted by using the Google Scholar database. Various keywords were used to find the targeted papers. The keywords are presented in Table 1. Combinations of these keywords were used to search for the targeted articles. Based on this research 187 studies were selected for further investigation, and from these set of articles, 42 have met all of the inclusion criteria, which resulted in 32 different intervention programs. However, at the end when it appeared that only one study focused on vocabulary, another search specifically for vocabulary interventions was done to make sure that it is not due to the used keywords. Surprisingly, no additional vocabulary study that meets the inclusion criteria was found.

Finally, 41 articles were identified for this review. Fig. 1 depicts the distribution of published papers based on their journals. Category Others indicates the number of journals which represent only one study in the review. Note that Computers and Education, Reading and Writing, Journal of Research in Reading and Dyslexia are the most represented journals. This figure shows a high dispersion of the publications over journals dealing with different research domains such as education, psychology, and technology.

Fig. 2 summarizes the reviewed publications and shows their distribution over periods of three years. This figure shows the growing interest in using technology to remediate the reading difficulties of early readers. Given the importance of the matter and the fact that various technologies with the potential to be utilized for educational purposes have become more accessible and ubiquitous over time, it is not surprising to observe this upward trend. 
Table 1

Keywords used for the research procedure.

\begin{tabular}{|c|c|c|c|}
\hline Category 1 & Category 2 & Category 3 & Category 4 \\
\hline $\begin{array}{l}\text { - Technology-Assisted } \\
\text { - Technology-Based } \\
\text { - Computerized } \\
\text { - Computer-Assisted } \\
\text { - Computer-Based } \\
\text { - Tablet } \\
\text { - Mobile } \\
\text { - Smartphone } \\
\text { - Virtual Reality } \\
\text { - Augmented Reality }\end{array}$ & $\begin{array}{l}\text { - Reading } \\
\text { - Literacy } \\
\text { - Dyslexia }\end{array}$ & - Intervention & $\begin{array}{l}\text { - Elementary } \\
\text { - Primary }\end{array}$ \\
\hline
\end{tabular}

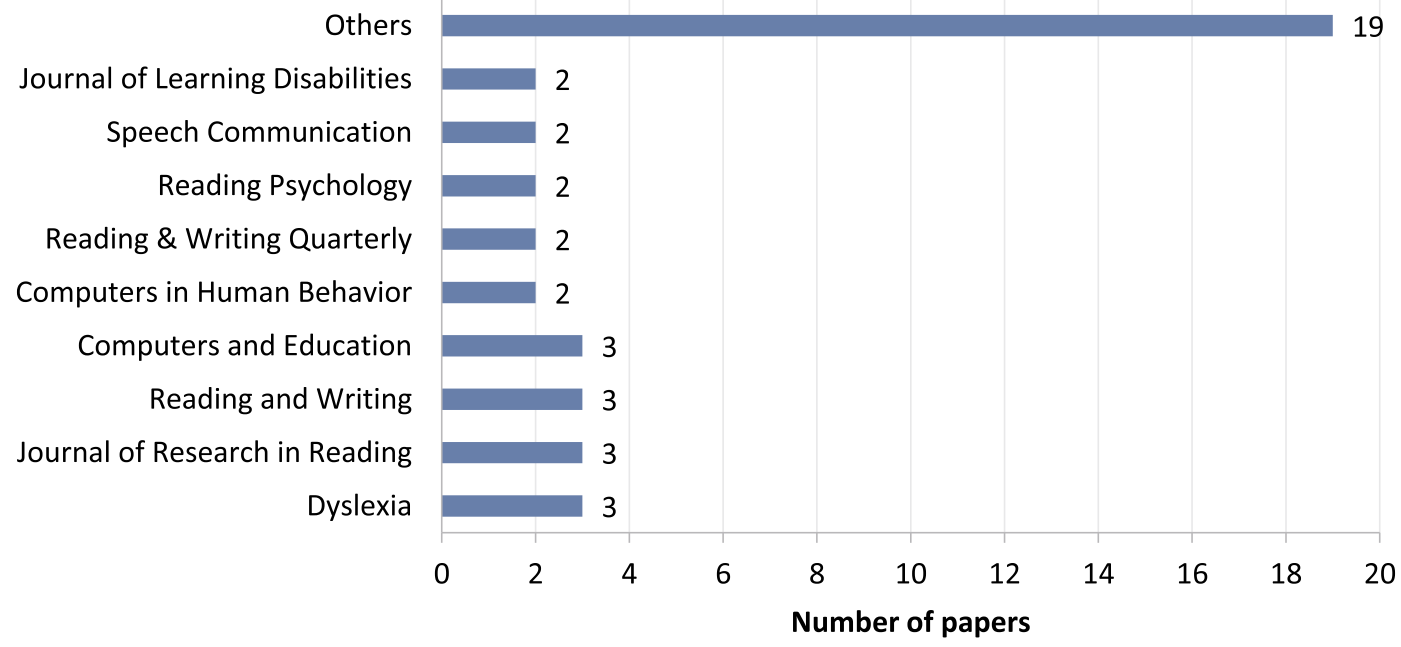

Fig. 1. Distribution of reviewed papers by journals.

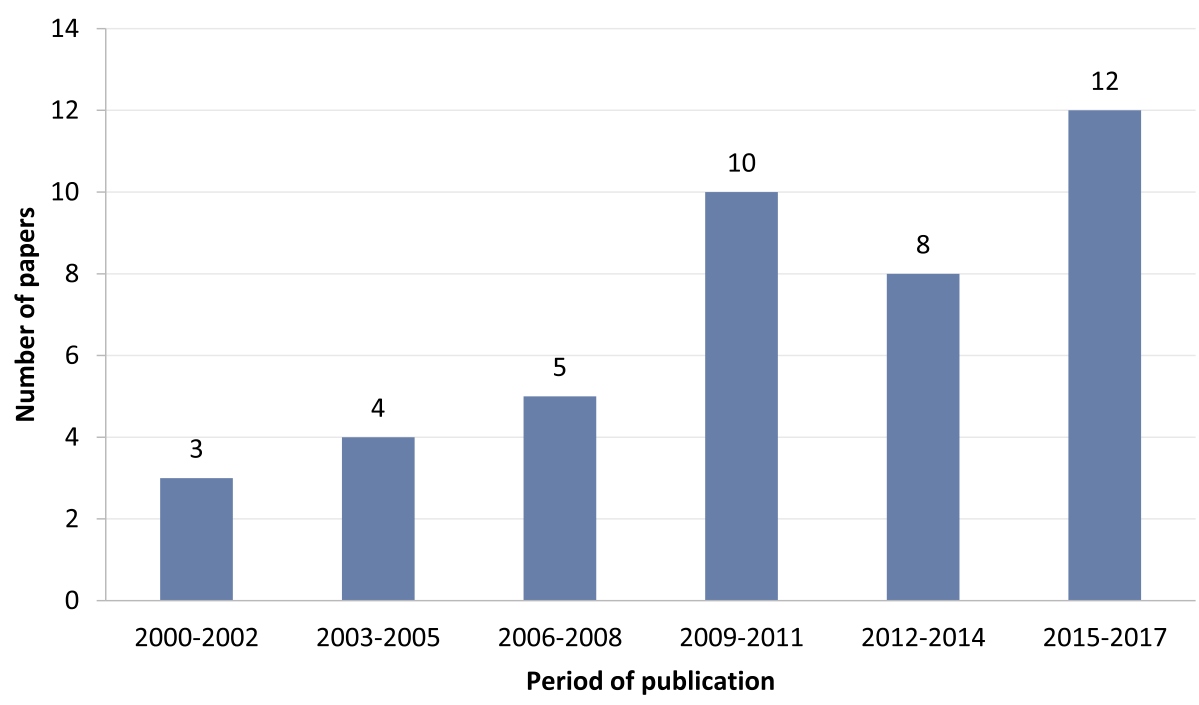

Fig. 2. Distribution of reviewed papers by year.

\subsection{Inclusion criteria}

The principal inclusion criteria for this review are:

- All of the participants should be in elementary grades or between the ages of 6-12 years old. 


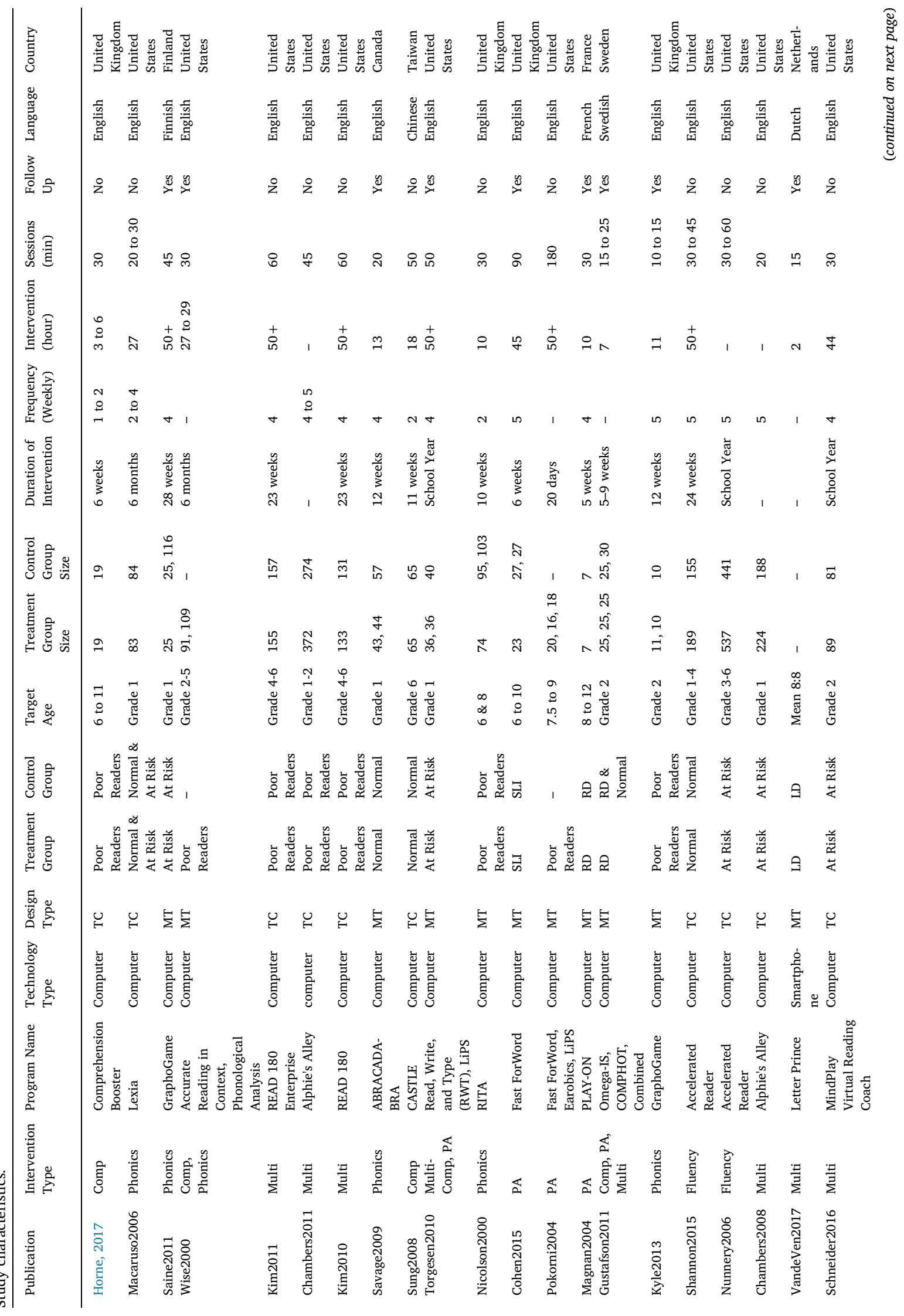




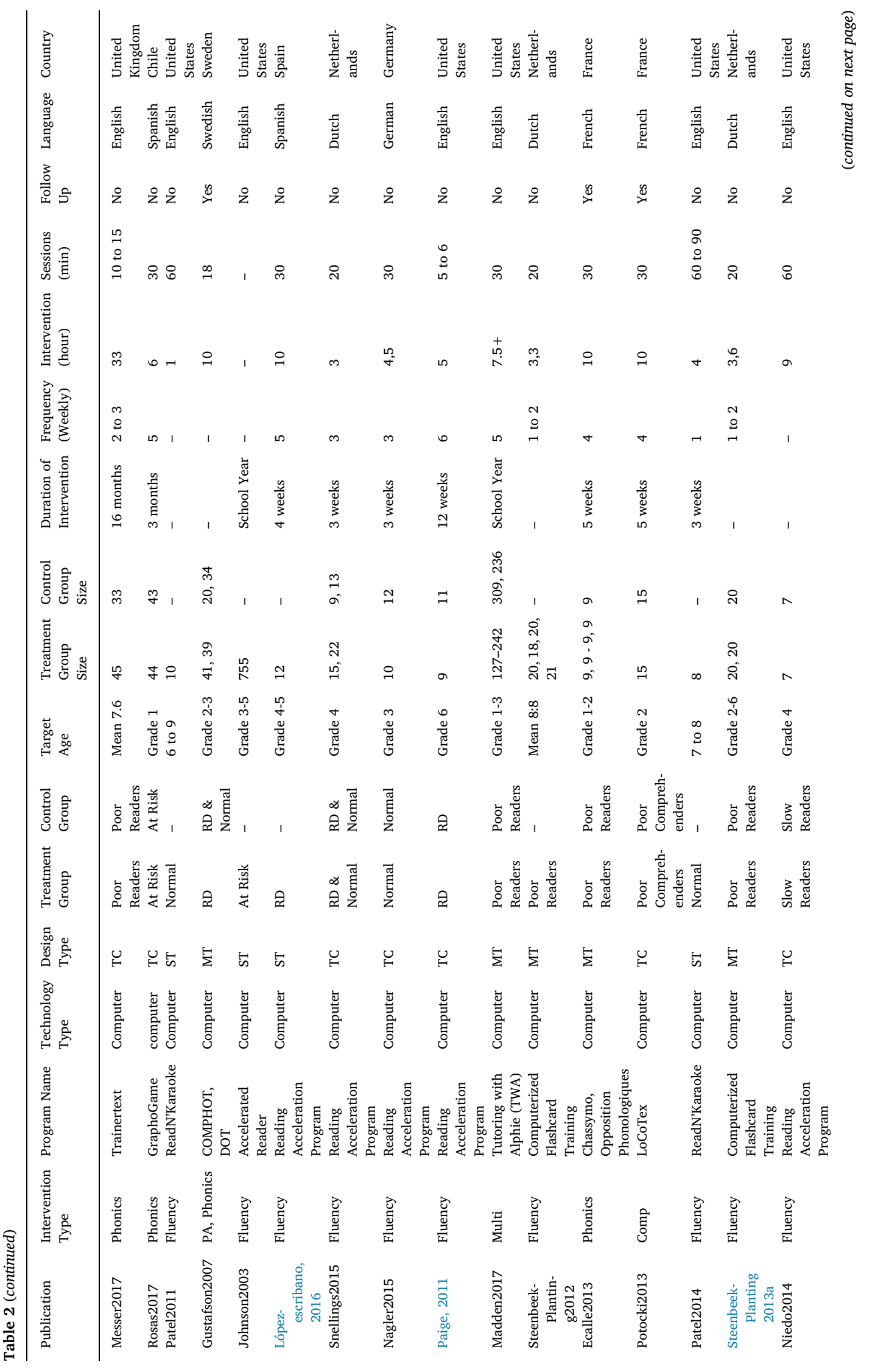




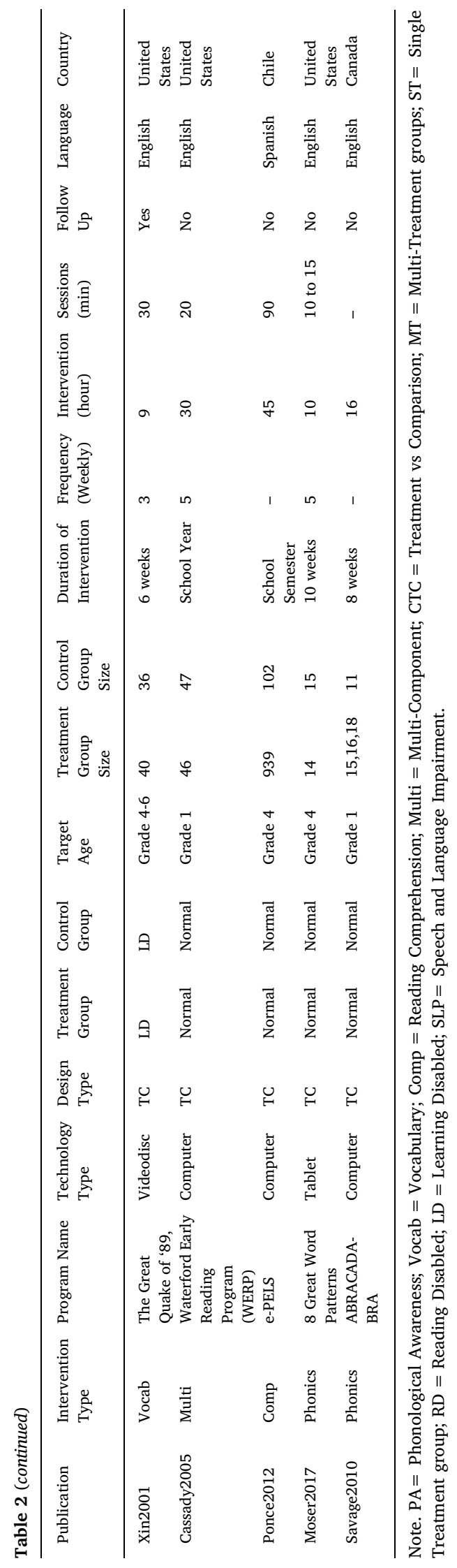


- The purpose of intervention completely or partially should be about improving reading acquisition.

- The intervention should be based on or assisted by technology.

- The intervention should be carried out on the reading acquisition of first language and studies focusing on second language learning are excluded.

- The intervention should be based on explicit reading instructional approaches.

- The study should include at least five participants in the intervention.

- The study should be published between 2000 and 2017.

\subsection{Coding procedure}

In Table 2, the characteristics of the reviewed studies are presented. Articles were categorized based on their intervention types, that is aligned with the report from National Reading Panel (2000), which means the main categories were phonological awareness, phonics, vocabulary, comprehension, and fluency. In addition, the multi-component category has been added to represent the intervention programs that target multiple of these key reading categories. Furthermore, the phonological awareness training programs who heavily involved written letters were put in the phonics category. For the design type of the studies, they are classified into three categories of Treatment vs. Comparison groups (TC), Multi-Treatment groups (MT), and Single-Treatment group (ST). In addition, the number of participants in each treatment or control group is written separately. Multiple treatment or control groups are separated by comma, and groups from multiple experiments in one study are separated with dash. The groups who received the traditional teaching instruction were considered as control groups. Finally, if total time of intervention (hours) was not explicitly mentioned in the study, it was estimated by simply multiplying the number of weeks, frequency of sessions per week, and duration of each session (if available).

\section{Results}

Overall, 42 number of studies have met the inclusion criteria. The reading programs used in these studies are classified based on their intervention types, which include phonological awareness, phonics, vocabulary, reading comprehension, fluency, and multicomponent. For each category, it begins with a brief introduction to each intervention type without considering the use of technology, and then, each technology-based intervention program existing in that category is described, alongside the results of the interventions. Moreover, additional research that did not meet the inclusion criteria is discussed at the end of this chapter. Finally, the important details and characteristics of these studies are brought in Table 2.

\subsection{Phonological awareness}

Phonological awareness (PA) is "the understanding of different ways that oral language can be divided into smaller components and manipulated" (Chard \& Dickson, 1999). That means having the capabilities such as isolating, identifying, segmenting, blending, deleting, adding or substituting the sounds of the smaller units of language such as word, syllable, onset, rime and individual phonemes. Phonemic awareness is one of the building blocks of phonological awareness, which is the ability to attend to and manipulate individual phoneme sounds. The other components of phonological awareness are syllable awareness and onset-rime awareness (Treiman \& Zukowski, 1991, pp. 67-83). In the literature, sometimes the term phonemic awareness has been used to signify phonological awareness.

Phonological awareness at early ages has been proven to be a strong predictor of reading proficiency at later years (Pennington \& Lefly, 2012; Scarborough, 1991). Furthermore, one of the most widely accepted theories of dyslexia describes this disability as a phonological deficit disorder (Ramus, 2003; Snowling, 2001). Particularly, it is the phonemic awareness subset that has been identified to be the key to reading success (Melby-Lervåg, Lyster, \& Hulme, 2012). According to the report of National Reading Panel (2000), interventions on teaching phonological awareness in small groups have been more effective than classroom size interventions, and additionally, focusing on one or two phonological awareness skills throughout the intervention will result in larger effect sizes than teaching three or more phonological awareness skills. Furthermore, it is suggested that involving written letters to manipulate phonemes, will result in better outcomes, especially for older children (Ehri, Nunes, Willows, et al., 2001).

Below, the interventions that aimed at improving phonological awareness by using technology are summarized, and their effects are briefly mentioned.

\subsubsection{LiPS}

Torgesen, Wagner, Rashotte, Herron, and Lindamood (2010) used Lindamood Phoneme Sequencing Program for Reading, Spelling, and Speech (LiPS; Lindamood, Lindamood, \& Truch, 1998) which aims at improving the phonemic awareness of children explicitly by teaching them the articulatory gestures of different phonemes. In addition, the user could do other activities such as tracking phonemes in words to reinforce their phonemic awareness, by using mouth-form images, color blocks and letters associated with different phonemes. Once children's skills in phonemic awareness are solidified, they can go on with advanced activities such as reading and spelling. The Intervention group throughout the immediate posttest and the follow up performed significantly better on measures of phonemic awareness, phonemic decoding, and rapid automatized naming. Pokorni, Worthington, and Jamison (2004) have also examined LiPS and found significant gains in PA, especially for blending and segmenting phonemes, but no transfer to reading or language measures was observed. Finally, it was more effective than the other treatment groups who used Fast ForWord or 
Earobics.

\subsubsection{Fast ForWord}

Pokorni et al. (2004) evaluated three different literacy programs focusing on phonological awareness teaching. Among these three, was Fast ForWord (FFW; Scientific Learning Corporation, 1997), that is an intervention program based on internet and CDROM, which includes various activities using acoustically processed speech and speech sounds. These activities target various skills such as phoneme discrimination, listening comprehension, working Memory and auditory word recognition. The gains of this intervention were limited to phonological awareness, and a transfer to reading or language measures was not found. In addition, it was less effective than the other two treatment groups that used other PA programs called LiPS and Earobics. Cohen, Hare, Boyle, and Mccartney (2015) tested FFW with children suffering from severe mixed receptive-expressive specific language impairment, but it showed no more benefits than the comparison groups. The effectiveness of FFW has been evaluated throughout many other studies. A meta-analysis on its effectiveness concluded that there is no evidence that FFW is an effective treatment for children's oral language or reading difficulties (Strong, Torgerson, Torgerson, \& Hulme, 2011).

\subsubsection{Earobics}

Pokorni et al. (2004) also evaluated a gamified phonological awareness program called Earobics (Cognitive Concepts, 1998), which has two sets of gamified activities in step 1 and step 2 to teach Phonological Awareness systematically. However, just the step 2 activities were tested in that study, which consists of games for auditory memory, sound recognition, segmenting sounds, blending sounds, discrimination of vowel and consonant sounds and recognizing word endings and beginnings. The intervention gains, however, were limited to phonological awareness, especially in segmenting phonemes, and a transfer to language or reading measures was not found.

\subsubsection{PLAY-ON}

Magnan, Ecalle, Veuillet, and Collet (2004) tested a computer software called PLAY-ON (Danon-Boileau \& Barbier, 2000) which consists of several gamified phonological awareness training activities. In their study, they just evaluated one audio-visual exercise of the software, called basket game, which aims at helping children to discriminate the sounds of similar phoneme pairs such as/p/-/b/ ,/t/-/d/and/k/-/g/. The sound of a CV syllable (e.g.,/ba/) is played to participants, and then after they listened to the sound, a basketball falls from the top of the screen and then, they should choose the basket with the right orthographical representation of it (ba or pa). In the end, from training this game, they found positive effects on a word recognition test. Their result was consistent with the result of studies that suggested phonological awareness training with letters is more effective than speech-only approaches (Ehri, Nunes, Willows, et al., 2001).

\subsubsection{COMPHOT}

Gustafson, Fälth, Svensson, Tjus, and Heimann (2011) evaluated a computerized phonological training program named COMPHOT (Ferreira, Gustafson, \& Rönnberg, 2003). It includes four sections which are Rhyme (four exercises), Position (eight exercises), Addition (five exercises), and Segmentation (three exercises). The exercises are mainly phonological and sound-based, along with a large number of pictures and limited use of written letters and words. Whenever the child clicks on a picture, the corresponding word will be played by a natural, recorded voice. An example of tasks is that participants hear a word, and then, they should choose the picture that rhymes with the heard word, or for instance, they should choose a (picture that has the same initial phoneme as the heard word. In addition, game-like elements such as showing high score are incorporated into exercises. After the intervention, the post-test results revealed that it had large effects on reading comprehension, word decoding, and sight word reading; a large to moderate effect on passage comprehension; and a moderate to small effect on pseudoword reading. However, post-test and follow-up results showed that intervention was more effective and persistent when it was coupled with reading comprehension instruction (Fälth, Gustafson, Tjus, Heimann, \& Svensson, 2013). Furthermore, results of another intervention study on COMPHOT revealed large effects on word decoding and text reading and moderate to large effects on phonological awareness (Gustafson, Ferreira, \& Ronnberg, 2007).

\subsection{Phonics}

Phonics refers to "various approaches designed to teach children about the orthographic code of the language and the relationships of spelling patterns to sound patterns" (Stahl, 1992). It is recommended to use a systematic and explicit approach to phonics for teaching early literacy skills (National Reading Panel, 2000). In addition, it has been indicated that interventions relying heavily on phonics are more effective for dyslexia remediation (Peterson \& Pennington, 2015). There exist different approaches to phonics, including synthetic phonics (blended phonics), analytic phonics, embedded phonics, analogy phonics, onset-rime phonics, and phonics through spelling (Ehri, Nunes, Stahl, \& Willows, 2001).

Synthetic Phonics which is the most widely accepted approach in English speaking countries is "an approach to the teaching of reading in which the phonemes associated with particular graphemes are pronounced in isolation and blended together (synthesized)" (Torgerson, Brooks, \& Hall, 2006; Wyse \& Goswami, 2008). However, in analytic phonics, phonemes associated with graphemes are not pronounced in isolation, and letter-sound associations are taught after the word has been recognized (Ehri, Nunes, Stahl and Willows, 2001; Torgerson et al., 2006). Embedded Phonics is an implicit approach which teaches letter-sound relations through the context of reading comprehension (Mesmer \& Griffith, 2005; Vaughn et al., 1999). Analogy phonics is an approach that uses parts of already learned words to acquire and decode new words (Ehri, Nunes, Stahl, et al., 2001). Onset-rime phonics as its 
name suggests is learning letter-sound associations through detecting the sound of letter or cluster of letters before the initial vowel (onset) and the sound of the rest of the word (rime; Torgerson et al., 2006). Finally, in phonics through spelling, students learn lettersound associations by segmenting words into phonemes and then by writing letters of the individual phonemes to build words (Ehri, Nunes, Stahl, et al., 2001).

Technology-based phonics interventions found in this review are summarized below, alongside their intervention outcomes.

\subsubsection{Lexia}

Macaruso, Hook, and McCabe (2006) utilized computer software called Lexia (Lexia Learning Systems, 2001) for their Literacy teaching intervention. It consists of two different programs, one called Phonics Based Reading (PBR), and the other, Strategies for Older Students (SOS). PBR consists of 3 levels, 17 skill activities, and 174 units. Phonics-based activities are highly structured and systematic, and they include multisensory tasks like audio-visual matching and kinesthetic responses. Before that student can work independently on the activities, the teacher should set the initial level of the program. After finishing PBR activities, students can go on to SOS activities, which has five levels, 24 skill activities, and 369 units. It starts by building on the user's phonics knowledge, and it advances throughout the levels. Finally, the results of the intervention showed that children in the treatment group had improved their reading skills more than the control group, but the difference was not significant. However, if the comparison is limited to 'at risk' students, the improvement in the treatment group is significantly more than the control group.

\subsubsection{GraphoGame}

In their computer-assisted reading intervention, Saine, Lerkkanen, Ahonen, Tolvanen, and Lyytinen (2011) used a phonics-based Finnish program called GraphoGame (also known as Ekapeli or Literate; Hintikka, Aro, \& Lyytinen, 2005; Lyytinen, Erskine, Kujala, Ojanen, \& Richardson, 2009; Lyytinen, Ronimus, Alanko, Poikkeus, \& Taanila, 2007). It consists of a range of gamified practices from pre-reading to fluency. Its primary objective is to build an automatic phonological-orthographical binding by focusing on training in matching speech sounds to their written counterparts (Ojanen et al., 2015). It starts with letter-sound relations and then it progresses to syllable level and the word and pseudoword levels. It is an adaptive program, and it adjusts the difficulty level of the activities to the performance of the user. Results of this study showed significant gains in letter knowledge, decoding, accuracy, fluency, and spelling.

In another study, Kyle, Kujala, Richardson, Lyytinen, and Goswami (2013) compared the two component of this program in English, which are GraphoGame Phoneme (GG Phoneme) and Graphogame Rime (GG Rime). Each component tries to systematically build the integration of speech sounds to their written forms, though, one at phoneme level and the other at rime level. Both interventions led to significant gains in reading, spelling and phonological skills. However, the effect size did not differ significantly between the two interventions. Furthermore, Rosas, Escobar, Ramírez, Meneses, and Guajardo (2017) evaluated the GraphoGame program with Spanish speaking children from both low and high socio-economic status (SES). Children with low SES showed an improvement in letter-sound knowledge, while the high SES children in the treatment group improved their Rapid Automatized Naming (RAN). However, no significant improvement was found in word reading, pseudoword reading and phonological awareness for both low and high SES children in the treatment group.

\subsubsection{Phonological Analysis}

Wise, Ring, and Olson (2000) used a computer-assisted intervention named Phonological Analysis. It consists of four sub-programs called Phonological Analysis with Letters, Nonword Choice, Marvin, and Spello. Phonological Analysis with Letters is designed to help children practice and learn letter-sound relations. Nonword Choice is an exercise in which a non-word was pronounced by the computer and then children should choose the right non-word between multiple choices that matched the pronunciation. Marvin is a similar task, in which an animated mouth pronouncing a non-word is shown, and then the user should decide whether it matched the displayed non-word or not, and if it did not match, what was the difference. Spello is a task in which the user should enter the right spelling of a word after hearing its pronunciation by the computer. In the process, the user can listen to the pronunciation of the entered word at any time to see if it matches the one pronounced by the computer. It aims at teaching the orthographical-phonological relations to children. All the tasks in this intervention are adaptive by automatically increasing or decreasing the difficulty level, depending on the user's performance. They compared this program with a computerized reading comprehension program (Accurate Reading in Context), and the results showed that Phonological Analysis program was more effective at improving the phonological skills, and the effect remained significant after the two years follow-up. However, for word decoding measure, the difference between the two programs was not significant.

\subsubsection{ABRACADABRA}

Savage, Abrami, Hipps, and Deault (2009) investigated ABRACADABRA, which is a web-based tool for improving literacy that can be accessed freely. The flexibility and customizability of ABRACADABRA allowed them to test and compare the effectiveness of two different approaches to phonics, which are Synthetic Phonics and Analytic Phonics. Synthetic Phonics intervention is aimed at building the skills for blending and segmenting words at phoneme level. Students were introduced to six letter-sounds each week and then they were able to build on their acquired letter-sound knowledge for developing the blending and segmenting skills by doing these activities: "Auditory Blending (blending sounds and choosing a matching picture); Blending Train (identifying a word by blending its letter sounds); Basic Decoding (sounding out and reading words); and Auditory Segmenting (matching words to their segmented sounds)“. Each of These activities contained different difficulty levels, and as students progressed, the more demanding levels were introduced to them. 
Analytic Phonics is aimed at improving skills in distinguishing and manipulating the onset and rime units of words. Letter-sound associations were presented to students at a slow pace, with the intention of allowing them enough time to practice and learn sound patterns thoroughly. This intervention approach consists of several activities which are: "Same Word (identifying similar words on the basis of their sound); Word Matching (matching word cards by their beginning sounds); Rime Matching (matching words that rhyme); Word Families (making words from the same word family by changing the first letter); and Word Changing (manipulating the onsets or other letters of words in rhyme families to form a new word)“. Finally, the results of this study revealed that both of the interventions had significant impacts on literacy scores. Analytic phonics had a marked impact on letter-sound knowledge, but synthetic phonics influenced more phonological awareness skills in both post-tests and fluency in the second post-test. In 2010, another study evaluated different implementation styles of ABRACADABRA, and they concluded that the Adaptation group who applied technology to broader learning themes, benefited the most from the intervention by improving their literacy skills the most (Savage et al., 2010). In 2015 a meta-analysis investigated the effectiveness of ABRACADABRA, and they found out that it was more effective on phonemic awareness, phonics, listening comprehension and vocabulary, but it was less effective for fluency and reading comprehension (Abrami, Borohkovski, \& Lysenko, 2015).

\subsubsection{RITA}

Nicolson, Fawcett, and Nicolson (2000) presented and evaluated a computer-assisted reading program for low readers, called Reader's Interactive Teaching Assistant (RITA). The teacher has a central role in this program for choosing and planning the activities that children should do. It used an alphabetically-arranged pad of buttons as an input, and output was in the form of text, picture, graphics and synthesized or digitized speech. It contained various phonics activities from individual phonemes to the word level. All of these activities along with a computerized version of books and sounds are available in the Resource Library component. The results showed a significant improvement in standard literacy scores in RITA group, in comparison to the control group. However, compared to the other group who received traditional instruction, it was slightly less effective.

\subsubsection{Trainertext}

Messer and Nash (2017) examined a computer system called Trainertext (Easyread, 2014) which uses visual mnemonics to teach graphene-phoneme relations. This method incorporates embedded picture mnemonics that can illustrate an object whose name starts with the target letter, or it can depict an object whose shape is similar to the target letter. In this study, for each English phoneme, a picture representing the phoneme is shown above it. For example, for the phoneme/a/in the word 'gas', the visual mnemonics of the Ant in Pink Pants is shown. Therefore, wherever the children struggle to decode, they can click on the letter to see the relevant visual mnemonics. As the children progress in decoding, the program increases the number of words that should be read, to establish the mastery of letter-sound knowledge. In order to increase the motivation of children, the system proposes some simple decoding related games, before and after doing the main activities. The results of the intervention showed that treatment had significant positive impacts on decoding, phonological awareness, naming speed, phonological short-term memory, and executive loaded working memory. However, they failed to find any meaningful effect on spelling.

\subsubsection{DOT}

Gustafson et al. (2007) examined a computerized orthographic training program, named DOT (Gustafson, Ferreira, \& Rönnberg, 2003), which includes four different sections containing a total of eleven exercises. These sections are word reading (four exercises), text reading (two exercises), word parts (two exercises), and building words (three exercises). The exercises are heavily based on written letters, morphemes, words and texts, as well as the link to their sounds. Therefore, users can click on written forms, and the computer sounds them out. In addition, game-like elements such as performance, high score list, and happy or sad auditory response feedback are included in the program. Results of the intervention showed an improvement in reading-related skills, notably large effects on word decoding and text reading and moderate to large effect on phonological awareness. However, there was not any statistically significant superiority to the comparison group who received ordinary special instruction.

\subsubsection{Chassymo}

Ecalle, Kleinsz, and Magnan (2013) ran experiments involving a software called Chassymo (Ecalle, Magnan, \& Jabouley, 2010), which focuses on training the grapho-syllabic relations in words. The student hears a syllable, then, $500 \mathrm{~ms}$ later, written form of the syllable will be displayed, and then, $500 \mathrm{~ms}$ later, the sound of a word will be played, now the student should choose if the syllable was present in the heard word or not, and if it was present, what was its position in the word (initial, median or final). Corrective feedback is displayed after the trial, by showing the word and highlighting the syllable in green. Its training set consists of 600 bisyllabic and tri-syllabic words. The results of this study revealed that this grapho-syllabic intervention was more effective than a grapho-phonemic program, on measures of silent and aloud word reading, as well as reading comprehension.

\subsubsection{Oppositions Phonologiques}

Ecalle et al. (2013) used a piece of software called Oppositions Phonologiques (Revy, 2005) in their reading intervention study. It aims at teaching the graphene-phoneme relations, by focusing on phonological oppositions such as $\mathrm{p} / \mathrm{b}, \mathrm{t} / \mathrm{d}$, and $\mathrm{m} / \mathrm{n}$. $10 \mathrm{phono-}$ logical oppositions are chosen for the program and for each one 50 pairs of words are included. The child is presented with the pair of written words differing in one phoneme, and then, one of the words is played, and the child should decide which of the two words was heard. Then, the corrective feedback was displayed by highlighting the correct word in green. The outcome data of this intervention study revealed that this grapho-phonemic approach was less effective on word reading and comprehension than a grapho- 
syllabic approach used by another treatment group.

\subsubsection{Great Word Patterns}

Moser, Morrison, and Wilcox (2017) evaluated a software application called 8 Great Word Patterns (Moser, 2012), which teaches the common word structures and patterns. It has eight levels of instruction, containing a total of 88 lessons. It focuses on one-syllable words, and it teaches students the common patterns of consonants, vowels, digraphs, and morphemes in words. It allows the students to manipulate word structures by using activities such as blending, segmenting, substituting and sequencing. After finishing these lessons, children went on to practice word identification in connected text. Finally, the outcome of the intervention showed no significant difference in rate and accuracy of oral reading and motivation to read, between the intervention and the comparison groups. However, the intervention group outperformed the control group on measures of spelling, vocabulary, and comprehension.

\subsection{Vocabulary}

Vocabulary is "the knowledge of meanings of words" (Kamil \& Hiebert, 2005). However, vocabulary knowledge is not only knowing the definition of the words, but also knowing how they fit into the world (Stahl, 2005). The correlational relationship between vocabulary and comprehension has long been established, and many studies have shown that vocabulary size at early ages is a strong predictor of reading comprehension later on (Cunningham \& Stanovich, 1997; Scarborough, Neuman, \& Dickinson, 2001; Sénéchal \& Ouellette, 2006).

Vocabulary size varies in individuals, even before entering the school the gap between children can be large (Hart \& Risley, 2003; Hoff, 2003) and unfortunately this gap tends to become larger as they grow (Biemiller \& Slonim, 2001; Hart \& Risley, 1995). The kids who have larger vocabulary knowledge, have better reading comprehension and tend to engage themselves more in reading activities and hence, they will acquire more vocabulary through incidental acquisition, and on the other hand, children with poor vocabulary knowledge, avoid extensive, independent reading activities because of their poor comprehension and thus, acquire less new words (Nagy, 2005). Therefore, it is vital to help students extend their vocabulary knowledge at early ages through long-term and comprehensive instruction (Nagy, 2005; Neuman \& Dwyer, 2009).

There are four types of vocabularies, which are listening, speaking, reading and writing vocabularies. The first two, build spoken vocabulary and the latter two, form written vocabulary. In addition, vocabulary knowledge can be divided into two categories of receptive and productive. Receptive vocabulary is those that a person can recognize through listening or reading, while productive vocabulary is the words that one can utilize during speaking or writing. Finally, sight vocabulary is a subcategory of reading vocabulary that does not require explicit word decoding (National Reading Panel, 2000). From the effective approaches for teaching vocabulary, we can mention direct or explicit instruction, using multimedia methods, teaching mnemonic strategies and instructing morphemic analysis (Kuder, 2017). Indirect instruction or simply encouraging children to engage themselves in extensive independent reading or reading aloud to them, which causes incidental acquisition of new words, is a vital part to vocabulary learning, as well (Cunningham, 2005, pp. 45-68). Effective instructions rely highly on multimedia aspects, richness of context in which vocabulary is learned, active engagement of children, and multiple exposures to words (National Reading Panel, 2000).

The section below presents the summary of the vocabulary interventions found in the reviewed papers. However, to our biggest surprise, only one paper that incorporated technology to instruct first language vocabulary is found.

\subsubsection{The Great Quake of ' 89}

Xin and Rieth (2001) evaluated a video-assisted vocabulary instruction by using a videodisc called The Great Quake of '89, which is created by ABC News and focuses on the 1989 San Francisco earthquake. It contains an hour of video content in 28 chapters. Thirty words were selected, which were depicted in the video and were suitable for teaching to target students with learning disability. The students watched the videos, as well as some other activities to reinforce the acquisition of the target words. These activities included a reading comprehension task with six narrative texts of 150 words length, each containing five of target words and 10 comprehension questions, as well as a sentence cloze task, in which students should fill in the blanks with target words, and finally, reading and discussing a set of illustrative sentences, each containing an underlined target word that also depicts a scene in the video. The results of the study showed that children in video-assisted group statistically outperformed non-video group on word meaning acquisition. However, no significant difference was observed in word generalization and reading comprehension.

\subsection{Reading comprehension}

Reading Comprehension is defined as "the construction of meaning of a written or spoken communication through a reciprocal, holistic interchange of ideas between the interpreter and the message in a particular communicative context. Note: The presumption here is that meaning resides in the intentional problem-solving, thinking processes of the interpreter during such an interchange, that the content of meaning is influenced by that person's prior knowledge and experience, and that the message so constructed by the receiver may or may not be congruent with the message sent." (Harris \& Hodges, 1995). Obviously, the ultimate goal of acquiring different literacy skills from phonemic awareness to vocabulary learning and fluency is to be able to comprehend texts efficiently and to produce texts that are comprehensible for others.

Since various skills are involved in proficient reading comprehension, a deficit to one or multiple of these skills can cause an impairment to the comprehension level. A source of comprehension difficulty can come from a deficit to one or multiple of these skills: lexical processes, working memory, cognitive inhibition, attention allocation, inference making, comprehension monitoring 
and knowledge, in which Lexical processes include phonological skills, semantic skills, and visual word recognition. (Kendeou, Van Den Broek, Helder, \& Karlsson, 2014; Nation, 2005). Therefore, each individual with reading comprehension difficulty can have a different underlying problem, resulting in a different reading profile (Cain \& Oakhill, 2006).

Plenty of studies have proposed and evaluated different reading comprehension intervention methods, but the most common interventions in the literature are those that try to teach readers some strategies to improve comprehension skills, such as comprehension monitoring, inference making, cooperative learning, question generating and answering, identifying main idea, summarizing, predicting, and recognizing the structure (Gersten, Fuchs, Williams, \& Baker, 2001; Mckeown, Beck, \& Blake, 2009; National Reading Panel, 2000). However, these strategies can differ for comprehension of narrative texts and comprehension of expository texts. For narrative texts, strategies such as using story maps, retelling the story, making predictions and answering comprehension questions can be taught. On the other hand, for expository texts, strategies like recognizing the structure, summarizing, main idea identification and graphic organizers can be used (Gersten et al., 2001).

Below, the technology-based reading comprehension interventions of this review are summarized, and their effects are mentioned.

\subsubsection{Comprehension Booster}

Horne (2017) used a computerized intervention program called Comprehension Booster (Lucid Research, 2010). It is created to ameliorate the reading and listening comprehension of 7-14 years old children. It consists of 70 fictions and 70 non-fiction passages. It has seven different difficulty level. Each passage will be followed by multiple-choice comprehension questions, and depending on the answers of the student, it can decide to change the difficulty level of the program or continue with the same difficulty level. The texts are accompanied by images, and the reader can select each word to hear the pronunciation, or to see its definition. It also includes asking questions and answering alongside immediate corrective feedback. The results of the intervention showed significant improvement in reading accuracy and comprehension for the intervention group.

\subsubsection{CASTLE}

Sung, Chang, and Huang (2008) presented and investigated a computer-assisted tool for teaching reading comprehension strategies to sixth-grade children. It is named CASTLE, which is the abbreviation of Computer Assisted Strategy Teaching and Learning Environment. They extended the Selection-Organization-Integration (SOI) model of text comprehension (Mayer, 1996) by proposing the model of Attention-Selection-Organization-Integration-Monitoring (ASOIM). This model formed the basis of their computerassisted strategy-teaching tool by allowing the students to learn and practice the strategies for each component of the model. For Attention component, they used self-questioning and error detection strategies to improve the concentration of the readers. For Selection component, concept map blank-filling and highlighting strategies are used in order to teach students to select important messages. For Organization component, concept map correction and inference blank-filling strategies have been used to teach students the way to organize the messages in an article. For Integration component, proposition-combining and summarization strategies have been incorporated to teach students how to integrate the knowledge gained from reading the texts. Finally, the monitoring strategy of the Monitoring component is aimed at teaching the readers to monitor their performances while performing previous strategies. For facilitating the interaction of the user, an agent using voice instruction was incorporated to guide the users through work procedure, the interface, and feedback. Finally, the results of the intervention showed that the experimental group outperformed the control group in reading comprehension and the use of comprehension strategies.

\subsection{3. $-I S$}

Omega-IS (Omega-Interactive Sentence; Heimann, Lundälv, Tjus, \& Nelson, 2004) is a reading comprehension training program tested by Gustafson et al. (2011). Its focus is on word and sentence level of reading. It begins from two-word sentences (noun + verb) and three-word sentences (noun + verb + noun), and it reaches to the level of constructing stories by choosing between different characters and scenarios for increasing the engagement and motivation of the child. The participant clicks on text buttons containing words or phrases and constructs the sentence. Then, a pre-recorder human voice reads the sentence, and in addition, an animation illustrates it. The program contains more than 1900 possible sentences with speech and animation. The posttest results from the intervention revealed large effects on passage comprehension and sight word reading, large to moderate effects on word decoding and pseudoword reading, and moderate to large effects on reading comprehension. Though, post-test and follow-up results revealed that intervention was more effective and persistent when it was combined with phonological awareness instruction (Fälth et al., 2013).

\subsubsection{Accurate Reading in Context}

Wise et al. (2000) evaluated a computer-assisted reading comprehension program, called Accurate Reading in Context. Stories were available in ten directories, which corresponded to ten difficulty levels, and children chose stories from their appropriate grade level. During reading, if children could not read a word, they could click on the target word, and at first, it highlighted the word, and if it was a regular word, it was broken to segments to help the child pronounce it. If the child clicked on it again, the computer pronounced it itself. After the reading, children had to answer comprehension questions, and if they missed a question, the program brought them back to the corresponding section in the story. In addition, through teachers, children were presented with different strategies of reading comprehension, such as making predictions, generating questions and summarizing. Then, they were encouraged to incorporate these strategies into their computerized reading sessions. Finally, they compared the results of this intervention with the results of a phonics program (Phonological Analysis). They concluded that although it improved the literacy skills of 
children, it was less effective than the other approach in improving phonological skills. Furthermore, there were not any significant differences between two programs on word reading measures.

\subsubsection{LoCoTex}

Potocki, Ecalle, and Magnan (2013) examined a computer-assisted comprehension program, named LoCoTex. It consists of three modules with a total of 36 narrative texts of varying lengths and each having up to three non-fictional characters. The first module aims at strengthening the literal comprehension of children. The child reads the text and answers the multi-choice comprehension questions. If the child struggles to answer correctly, the passage containing the response will be highlighted, and the child has the chance to reread it and answer the question again. The second module aims at promoting coherence or text-connecting inferencing skills. It uses anaphoric resolution exercises, in which the child has to match the anaphoric substitute (e.g., "it", "the little girl") with its right referent (e.g., "the ball", "Anna"). The third module aims at fostering children's knowledge-based or gap-filling inferencing skills. In this module, after reading the text, children have to answer gap-filling questions, and if the answer was correct, they have to click on the words that lead them to this answer. Otherwise, if the answer was incorrect, the clue words will be highlighted and then the question will be asked again. The result of this study showed a lasting effect in listening and reading comprehension. However, the effects on vocabulary and comprehension monitoring were less distinct.

\subsection{6. e-PELS}

Ponce, López, and Mayer (2012) investigated the effectiveness of a computer-based system called $e$-PELS ("Programa de Entrenamiento en Lectura Significativa" or "Program in Deep Reading Comprehension"). It teaches multiple strategies for reading comprehension, including underlining, paraphrasing, self-questioning, text structure, summarizing, using interactive graphic organizers and finally conceptualizing strategies. Children start with reading a short text and then, with the help of the teacher they apply different strategies sequentially and systematically. The system contains 30 texts, but it is also possible for the teachers to add their own texts. The results of the intervention revealed that the intervention group improved their reading comprehension skills significantly more than the control group, and the intervention was more effective for low-achieving children.

\subsection{Fluency}

Reading fluency is the ultimate level that reading instructions aim to reach, and it has a bidirectional relationship with reading comprehension (Klauda \& Guthrie, 2008). Despite the apparent general familiarity with fluency, there have been several different definitions of it in the literature, which indicates that fluency is a complex and multifaceted construct (Hudson, Pullen, Lane, \& Torgesen, 2009). A more recent definition of fluency is "Fluency combines accuracy, automaticity, and oral reading prosody, which, taken together, facilitate the reader's construction of meaning. It is demonstrated during oral reading through ease of word recognition, appropriate pacing, phrasing, and intonation. It is a factor in both oral and silent reading that can limit or support comprehension.“ (Kuhn, Schwanenflugel, \& Meisinger, 2010).

Reading fluency integrates every process, skill and subskill in reading (Wolf \& Katzir-Cohen, 2001), but broadly speaking it consists of three components of accuracy, automaticity, and prosody (Calet, Gutiérrez-Palma, \& Defior, 2016; Erekson, 2003; LaBerge \& Samuels, 1974; Rasinski, 2006). Automaticity is defined as "fluent processing of information that requires little effort or attention" (Harris \& Hodges, 1995). On the other hand, prosody refers to "stress, rhythm, intonation, and pause structure in speech and serves a wide range of linguistic and affective functions" (Patel \& McNab, 2011).

There have been various intervention approaches for reading fluency, but according to the report of National Reading Panel (2000), most of them fall into these two categories of repeated oral reading practice and those approaches that try to increase independent or recreational reading. The first category includes repeated reading (Samuels, 1979), neurological impress (Heckelman, 1969), radio reading (Greene, 1979), paired reading (Topping, 1987), etc. The second category includes approaches such as sustained silent reading (Hunt, 1970) and accelerated reader (Renaissance Learning, 1986). Finally, in their review of fluency interventions, National Reading Panel has concluded that repeated oral reading approaches have proven to be more effective than other approaches. More recent review studies have come to the same conclusion by admitting the effectiveness of repeated reading approach (M. K. Kim, Bryant, Bryant, \& Park, 2017; Lee \& Yoon, 2017; Stevens, Walker, \& Vaughn, 2016).

Below, the instructional mechanisms of the computerized fluency interventions found in the reviewed papers, as well as the outcome of their interventions are summarized.

\subsubsection{Accelerated reader}

Nunnery, Ross, and McDonald (2006) evaluated Accelerated Reader (AR; Renaissance Learning, 1986) which has been widely used in thousands of United States' schools throughout the years. It is a computer-assisted program that helps teachers and students to monitor, motivate and personalize the practice of reading. It provides comprehension quizzes at the end of each reading material, and through this feedback, it determines the reading level (zone of proximal development) of the student, and then, other reading materials matching this level will be available to be selected for future reading. Meanwhile, the teacher has access to the information such as results of quizzes, reading level, and amount of words read by the student. Thus, at any time if a student is struggling, the teacher can decide to intervene by monitoring the student more closely or providing more personalized instruction. The reading practices can be in three forms. The materials can be read to the students (reading aloud); it can be read with the students (paired reading), or it can be read independently by the students. Nunnery et al. found that students using accelerated reader exhibited significantly higher improvement rate in reading achievement, in comparison to the control group. In addition, they concluded that 
the effect was higher among lower grades. Furthermore, it reduced the negative effect of learning disability among those students. Shannon, Styers, Wilkerson, and Peery (2015) also evaluated Accelerated Reader across some elementary grades and concluded that students engaged in this computerized approach, exhibited statistically significant positive impact on their reading achievement. Additionally, another intervention study on AR showed that high AR users had a significantly higher improvement in their reading comprehension than low or average AR users (Johnson \& Howard, 2003). Finally, the report from National Literacy Trust (Clark \& Cunningham, 2016) indicated that in comparison to the students who did not use accelerated reader, the ones who used it enjoy reading more, read more frequently, and think more positive about reading.

\subsubsection{Reading Acceleration Program}

López-escribano (2016) tested Reading Acceleration Program (RAP; Breznitz \& Nevat, 2004) with Spanish dyslexic children. It is aimed at improving the reading fluency by increasing the reading rate. First, after allowing the user to read a certain amount of text at self-pace and answering the corresponding comprehension questions, it calculates the user's current reading rate and next time, the text will begin disappearing letter by letter from the start of the sentence at a pace relevant to the reading rate of the user. Multiple choice comprehension questions will follow each reading task. If the user answers them $100 \%$ correctly, the program will increase the pace of text disappearance with a small increment. If the user answers comprehension questions wrongly (less than 80\%), it will decrease the speed of text disappearance. Finally, if the user answers the questions between $80 \%$ and $100 \%$, it will not change the pace of the text disappearance. In that study, López-Escribano concluded that this intervention could improve the reading rate of proficient comprehenders while maintaining their comprehension level and it can increase the comprehension level of poor comprehenders, albeit without improving their reading rate. This approach was tested in a study involving English children with reading disability, and it was successfully improved the fluency sub-processes of children, but it was not more effective than the traditional repeated reading method used by control group (Paige, 2011). Another study using RAP concluded that intervention resulted in an improvement on comprehension level of reading disabled Dutch children during fast-paced reading (Snellings, van der Leij, de Jong, \& Blok, 2015). Furthermore, another study on using this text-fading approach with German children showed that children in treatment group significantly improved their sentence reading fluency in a standardized reading test (Nagler et al., 2015). In another study, RAP was accompanied with the instruction of a set of self-regulation of attention and engagement strategies and the results showed that the group using RAP significantly improved their silent sentence reading rate, as well as lexical comprehension (Niedo, Lee, Breznitz, \& Berninger, 2014).

\subsubsection{Computerized flashcard training}

(Steenbeek-Planting, van Bon, \& Schreuder, 2012) have tested a computerized flashcard training approach (Van Den Bosch, van Bon, \& Schreuder, 1995), which displays single words with phonological CVC structure, one at a time with a limited exposure time, and students are instructed to sound out the words as fast as they can. The experimenter records the correctness of verbal responses and, the response times are recorded in the computer so that the system can automatically adapt the exposure time of the words. In order to keep the accuracy level approximately constant, it decreases the presentation time if the student responds correctly to a certain amount of words, and it increases the presentation time if the student struggles to read aloud the words correctly. At each session, the student works on 100 words that are randomly taken from the training set. In one treatment group, every misread word was eliminated from the training set, so that the next time students only work on their past successes in addition to new words. However, in the other group, they did the opposite, and it was the correctly pronounced words, which were eliminated from further training so that the students can focus on their past failures, and the new words. The result of the intervention showed that it was effective in improving the word reading fluency and the effect transferred to untrained words as well. There was not a significant difference between the groups focusing on their successes or their failures. However, the children with lower initial reading level benefited more from focusing on successes, and conversely, the children who had higher initial reading level benefited more from focusing on their failures. However, results of another study using computerized flashcard training showed that children with low initial reading level improved more when focused on their failures and children with high initial reading level, improved more when focused on their successes (Steenbeek-Planting, Van Bon, \& Schreuder, 2013, pp. 281-291).

\subsubsection{ReadN'Karaoke}

(Patel \& McNab, 2011) assessed an oral reading software called ReadN'Karaoke, which aims at promoting fluency through a guided repeated reading approach but with particular attention to prosody. In order to increase reading expressivity, it manipulates text into different formats to represent each of fundamental frequency (pitch), Intensity (loudness), duration (length), and a combination of them. The spacing between characters and words are used to represent the duration of a word and pause between words, respectively. Three shades of font color (black, grey and light grey) is used to show the intensity variations of the text. Finally, the text is fitted to the fundamental frequency contours to represent pitch variations of the text. These manipulated text formats were extracted from the recordings of a fluent adult reader. During the training session, the student should read the text in standard and each of manipulated formats, as well as combination of them. Students can listen to the samples of a fluent adult reader and then read it by themselves. Their voice will be recorded; they can listen to it; also they will get the necessary feedback from the experimenter, and finally, they can reread and rerecord all over again. Results of this brief one session training showed that manipulated text, presenting fundamental frequency variations has produced the most expressivity in participants. However, there was not any significant difference in prosodic variations of standard reading between baseline and post-training. Later, the next version of this software replaced manipulated text formats with augmented text by overlaid cues of pitch, duration, and intensity (Patel, Kember, \& Natale, 2014). The results of a longer three-session training with this new version showed that participants transferred pitch and word 
duration variations to the standard reading of post-training session.

\subsection{Multi-component}

It is recommended for the interventions to contain explicit instruction in all key reading categories, including phonological awareness, phonics, vocabulary, comprehension, and fluency (National Reading Panel, 2000). There are multiple reasons for this. First, reading is a multifaceted skill that involves many different processes and all of them are important for becoming a skilled reader, and any impairment to each of these processes can lead to difficulty in reading. Second, every individual has a different reading profile, and not all of struggling readers are suffering from the same issue (Cain \& Oakhill, 2006). Therefore, a powerful intervention will cover all the aspects of reading to make sure no aspect is neglected. A more powerful reading intervention can assess each individual's weaknesses and strengths to provide a more personalized and tailored instruction.

Below, the multi-component reading intervention programs found in the reviewed papers are summarized, and their effects are briefly mentioned.

\subsubsection{READ 180}

(J. S. Kim, Samson, Fitzgerald, \& Hartry, 2010) utilized a computer-assisted program called READ 180, which includes various reading activities. It contains four different parts, which are Reading Zone, Word Zone, Spelling Zone and Success Zone. Reading Zone is a section, which provides basic phonics instruction; Word Zone tries to help children achieve fluent Word Reading; Spelling Zone tries to improve spelling abilities for target words, and lastly, Success Zone is a section in which children should answer comprehension questions, and it records their oral reading as well. The results of the intervention found no significant impact on measures of word reading efficiency, reading comprehension and vocabulary. However, in another study, J. S. Kim, Capotosto, Hartry, \& Fitzgerald (2011) evaluated the READ 180 Enterprise, and the results showed that the treatment group outperformed the control group on measures of vocabulary and reading comprehension, but not on spelling and oral reading fluency.

\subsubsection{Alphie's Alley}

Chambers et al. (2011) tested a computer-assisted tutoring system named Alphie's Alley (Danis, Rainville, Therrien, Tucker, \& Abrami, 2005), as an intervention for improving the literacy skills of struggling readers. Its basic function is to assess the individual's literacy performance, and then, to create an individualized plan tailored to their needs. It consists of 12 types of activities from various aspects of literacy. Here is the list of these activities: 1- Letter identification 2- Letter writing 3- Auditory blending 4- Auditory segmenting 5- Sight words 6- Word-level blending 7- Spelling 8- Story preparation 9- Tracking 10- Fluency 11- Comprehension Questions 12- Graphic Organizers. In addition, it utilizes embedded multimedia such as animation, picture, and video. Furthermore, through video vignette or written suggestions, it provides performance support to the tutors helping them address students' specific problems. The results of the study indicated that first graders in experimental group exhibited significantly more improvement in reading achievement in comparison to the control group who practiced one-to-one tutoring. However, second graders in the experimental group showed no significant difference to the control group. In another study, Chambers et al. (2008) evaluated the effectiveness of Alphie's Alley and the results revealed that students whose tutors fully implemented this computer-assisted tutoring program, showed significant improvement on measures of letter-word identification, word attack, and fluency, but no significant difference was found for comprehension. Results of another study (Madden \& Slavin, 2017) showed that tutoring with Alphie had a substantial positive effect on measures of reading, and also the effect size was larger for second and third grade participants than first graders.

\subsubsection{Read, write, and type}

Torgesen et al. (2010) evaluated computer-assisted instructions in order to prevent future failures in children at risk of dyslexia. In one of their computer-assisted instructions, they used a program called Read, Write, and Type which was created by Dr. Jeanine Herron (Herron, 1995). It is a program to teach basic literacy knowledge by practicing phonetic spelling and writing skills through using colorful animation, digitized speech, and an engaging storyline. It explicitly teaches phonological awareness, letter-sound association, and phonemic decoding. It also aims at improving the keyboard typing skill of young children. The results from the posttest and follow-up showed significant improvements in phonemic awareness, phonemic decoding, and rapid naming, in the intervention group in comparison to the control group.

\subsubsection{Letter Prince}

(van de Ven, de Leeuw, van Weerdenburg, \& Steenbeek-Planting, 2017) tested a mobile game for improving early literacy, called Letter Prince (Letterprins; Steenbeek-Planting, Boot et al, 2013) on measures of pseudoword reading, word decoding, fluency and reading motivation. Letter Prince is a reading game in which children have to help a character (Letter Prince) to slay a dragon and enter a castle. For this goal, by doing some reading exercises, the player helps the character to collect necessary items such as wooden sword or shield. There are four types of exercises in the game. The first is a graphene-phoneme conversion, in which a letter is displayed, and the child has to say it out loud, and test assistant will decide if the child said it correctly or not. The second exercise is a semantic categorization task, in which the children have to decide whether a word belongs to a certain category or not. The third exercise is a sentence verification task, which presents a short sentence, followed by a short question, and the child has to decide whether the sentence is semantically plausible or not. Eventually, the fourth exercise is a flashcard training that presents a letter or a word for a short amount of time and then after it disappears, the child has to indicate to the test assistant which word or letter was 
presented. The game incorporates several reward types including stars after completing each level, showing an encouraging prerecorded video, and virtual stickers. In addition, the difficulty of the game is adapted to child's ability level, in order to be neither too easy nor too difficult. The results revealed a positive effect for pseudoword reading and text reading fluency, but no effect was found for word decoding or reading motivation.

\subsubsection{MindPlay Virtual Reading Coach}

Schneider et al. (2016) evaluated an online reading program called MindPlay Virtual Reading Coach (MVRC; MindPlay, 2012). At first, through MindPlay Universal Screener, it assesses the reading skills of children and then it creates an individualized syllabus for each student, containing direct, systematic and explicit instructions on phonemic awareness, phonics, vocabulary, comprehension, fluency, and grammar, aligned with common core standards (National Governors Association, 2010). In addition to interactive lessons, it also provides pre-recorded videos from reading specialists and speech pathologists. Large effect sizes have been observed for the overall intervention, reading fluency and non-word spelling, whereas a moderate effect size was found for real word spelling. However, this study failed to find any significant effect size for non-word and real word reading.

\subsubsection{Waterford Early Reading Program}

(Cassady \& Smith, 2005) investigated the effect of Waterford Early Reading Program (WERP) on first graders' reading skills. It is an adaptive computer program that integrates the class-based assessments, instructional activities and instructional materials for a systematic approach. It covers all the key reading components of phonological awareness, phonics, vocabulary, comprehension, and fluency. It has three levels, with each level containing instructional activities for a full year, as well as take-home activities. The results of the intervention showed that children in the intervention group outperformed the ones in the comparison group and the intervention was more beneficial for children with low initial reading level.

\subsection{Additional research}

Although no conference paper met the inclusion criteria, it is important to mention that they are a valuable source of information in designing technology-based reading interventions. Most of the conference papers are mainly focused on the developed technological approaches. They describe the innovative methods to remediate reading difficulties, but in general, they do not include experimentation to validate their approaches. However, for completeness, selected conference papers are included in this review.

Tzouveli, Schmidt, Schneider, Symvonis, and Kollias (2008) presented an adaptive assistive reading tool called AGENT-DYSL, which uses speech and image recognition to detect both the error types and the affective state of the individual. Then, based on the created profile of the user and the re-evaluation sessions, it provides the assistive functions such as changing font attributes, highlighting, and pre-emptive reading.

C.-Y. Lin, Yu, Chen, Huang, and Lin (2016) explored the use of a Mobile Augmented Reality (MAR) application called Aurasma, which interposes virtual objects on the real-world environment via camera. It scans the words on flash cards and shows related educational materials such as videos, animation or data.

Daud and Abas (2014) described a mobile app called Dyslexia Baca that is developed based on the ADDIE model, which has five phases of Analysis, Design, Development, Implementation, and Evaluation. It is intended to teach Malay letter recognition to dyslexics by emphasizing the identification of confusing letters, such as letters/p/and/b/.

Rello, Bayarri, and Gorriz (2012) presented a game application called Dyseggxia that used the analysis of errors written by dyslexics to design their exercises. It consists of five phonics activities for Spanish, which are insertion, omission, substitution, derivation, and separation. In addition, three different levels of difficulty are created such that when the level of difficulty is increased, less frequent and longer words with more complex morphology are used (Luz Rello, Bayarri, \& Gòrriz, 2013).

Bittencourt, Savino, Fernandes, and Boueri Rebello (2016) described the workflow of developing a mobile application targeting 6-9 years old dyslexics. The design process was started by observing the speech therapists' sessions with dyslexic children, and then, based on the observed activities two digital games called Corrida and Memória are developed, addressing syllable awareness and working memory, correspondingly. In addition, they have outlined the principles of mobile accessibility for dyslexics in terms of text, layout, and navigation.

\section{Analytical vision of the reviewed work}

This paper has identified and reviewed studies on technology-based and technology-assisted reading interventions for elementary grades. The review resulted in 42 articles and 32 programs. Thus, in this article, the content and instructional mechanisms of reading intervention programs were summarized, alongside the outcome of their interventions. The important details and characteristics of these studies are brought in Table 2 . In this section, different aspects of reading intervention studies are analyzed.

\subsection{Measures}

Since there were many differences in study designs and too many different variables were involved in these studies, it was considered that conducting a meta-analysis would not bring sufficiently reliable results. Apart from the author-devised measures, 72 different measures were found that have been used 117 times over the studies. Fig. 3 shows the measures that have been used the most. These frequently used measures are: Test of Word Reading Efficiency (TOWRE; Torgesen, Rashotte, \& Wagner, 1999), 


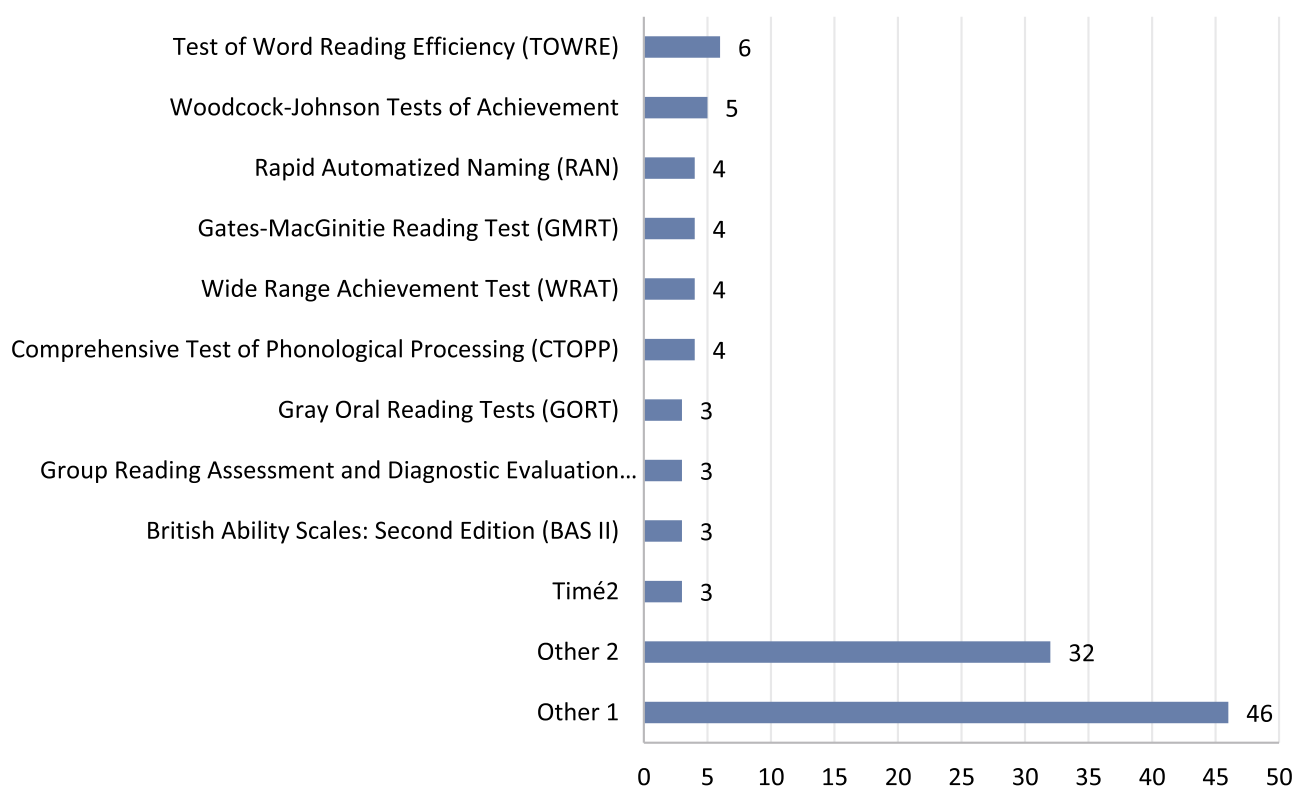

Fig. 3. Frequency of the measures throughout the studies.

Woodcock-Johnson Tests of Achievement (Schrank, Mather, \& McGrew, 2014; Woodcock, McGrew, \& Mather, 2001), Rapid Automatized Naming (Denckla \& Rudel, 1974; Wolf \& Denckla, 2005), Gates-MacGinitie Reading Test (GMRT; Macginitie, Macginitie, Cooter, Cooter, \& Curry, 1989; MacGinitie, MacGinitie, Maria, Dreyer, \& Hughes, 2000), Wide Range Achievement Test (WRAT; Jastak \& Wilkinson, 1984), Comprehensive Test of Phonological Processing (CTOPP; Wagner, Torgesen, \& Rashotte, 1999), Grey Oral Reading Tests (GORT; Wiederholt \& Bryant, 1992, Wiederholt \& Bryant, 2001), Group Reading Assessment and Diagnostic Evaluation (GRADE; K. T. Williams, 2001), British Ability Scales: Second Edition (BAS II; Elliott, 1996), and Timé2 (Écalle, 2004). Category Other 1 in this figure represents the number of measures that are used only once in the review, and Other 2 represents the number of measures that are used twice.

Fifty percent of the studies used only the standardized measures, twelve percent only used author-devised measures, and thirtyeight percent used a combination of both. The analysis of measures based on the intervention types shows that multi-component studies had highest rates (70\%) in using only standardized measures, which is understandable, as they target several reading skills that can be evaluated by general reading tests and there is no need for author-devised measures. Fluency and phonological awareness (58\% and 50\%) are the next intervention types who used standardized measures more often. It might be due to the powerful existing measures for these two skills, or the generality of these two skills, which can be evaluated as a whole. However, a smaller number of phonics studies (33\%) used only standardized measures, and it might be due to the difference in phonics interventions, as different skills were targeted, from phoneme-graphene matching to using bigger chunks such as morphemes, syllables, and whole words. Comprehension (16\%) used a lower amount of purely standardized tests because most of the comprehension studies tried to teach certain comprehension strategies to the children, and alongside evaluating the comprehension skill, some authors devised tests to measure how good they learned to apply the taught strategies. Only one vocabulary intervention is used in the review, but generally vocabulary interventions use mostly author-devised tests (National Reading Panel, 2000), and it is due to the sheer amount of individual vocabulary knowledge, in comparison to the limited amount of vocabulary taught in an intervention, which makes it really difficult to have an impact on the general vocabulary knowledge measured by standardized tests, and this motivates the researchers to devise measures for limiting the tests to the taught words. Altogether, this leads to the conclusion that comparing the results of the technology-based reading tools can be conducted using meta-analysis, however, to be sufficiently reliable, it requires a significant number of published studies with rigorous experiment designs (i.e., studies must include a control group, randomization, etc.).

\subsection{Interventions}

As illustrated in Fig. 4, studies that used phonics, fluency or multi-component, hold bigger shares. It is normal that few studies used phonological awareness intervention, because this approach is most effective in pre-elementary education and when children start elementary grades, it becomes less effective (Bus \& van IJzendoorn, 1999; Ehri, Nunes, Willows, et al., 2001). Thus, a significant number of the interventions focused on phonics by teaching phonological-orthographical matching.

Despite the high number of studies focusing on fluency, they have used only four different programs. This lack of variety may show the difficulty of designing a fluency-based intervention. When these four programs are looked more closely, it becomes more apparent that there is a lack of a well-rounded approach to fluency interventions. Flashcard training only works on word recognition automaticity, ReadN'Karaoke focuses solely on prosody, RAP concentrates on reading rate, and finally, AR is a reading practice monitoring system that encourages independent reading without providing any reading instruction. Therefore, none of the reviewed 


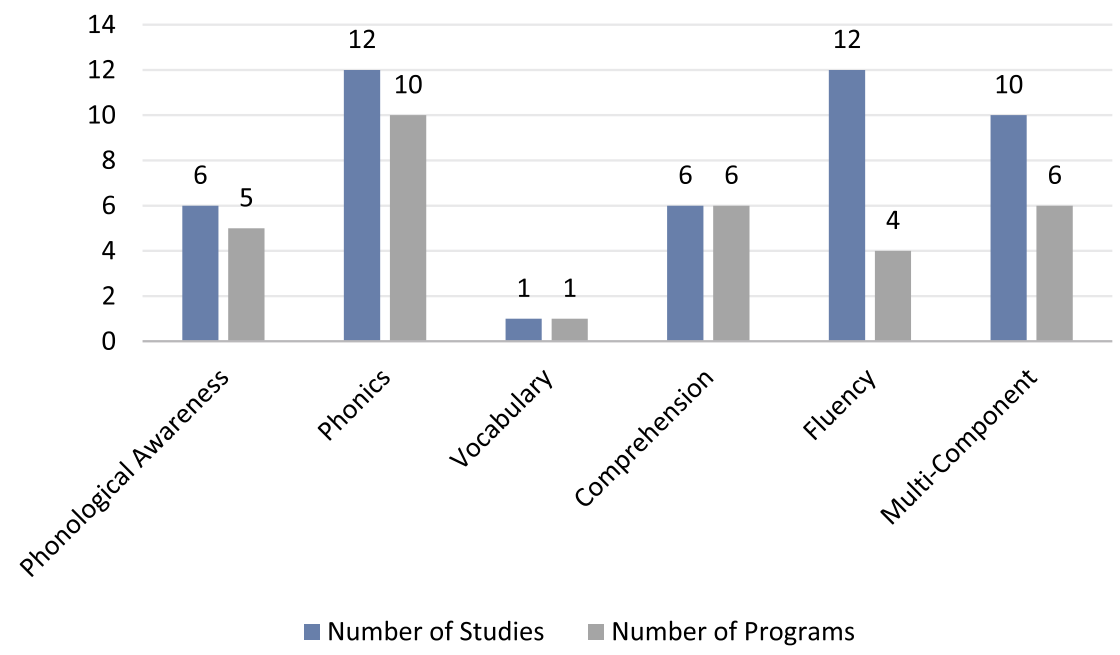

Fig. 4. Distribution of reviewed studies and programs based on intervention type.

programs provides a holistic approach for improving fluency, considering its complex and multifaceted nature. The use of technology to improve the automaticity and speed of reading can be really useful, especially because, automaticity and speed in reading needs mastery in multiple levels of decoding, but, in typical school conditions there is not enough practice for struggling readers to reach mastery levels in decoding (Vellutino, Fletcher, Snowling, \& Scanlon, 2004).

Despite the high variability of intervention programs in phonics, comprehension and phonological awareness, they are similar. For example, phonics interventions are mainly targeting phonological-orthographic matching, and comprehension interventions are specifically instructing certain strategies of comprehension. However, as mentioned previously, fluency intervention programs are very different; this explains the existing uncertainty about the effectiveness of the current fluency intervention approaches and the need for better solutions. Innovative approaches can automatically adapt themselves to the learner's capacity; they modulate the difficulty of challenges of the gamified context allowing the acquisition of automaticity. Gamified approaches are specifically useful for fostering fluency; they can motivate the learners, increase the adherence and engagement for long-time training leading to automaticity.

It is surprising that only one article on vocabulary intervention that met the inclusion criteria of this study was found. Despite knowing the prominent role of vocabulary knowledge on reading failure and its clear link with reading comprehension (Ouellette, 2006; Scarborough et al., 2001; Sénéchal \& Ouellette, 2006), it is surprising to see so few technology-based vocabulary interventions for early readers. It is more unexpected when one realizes that with the proven effect of multimedia on vocabulary learning (Abraham, 2008), it is the easiest reading category to teach through technology. There is an enormous amount of studies on vocabulary intervention for second language learning, which is completely normal, but, so few studies have examined the effectiveness of using technology to close the huge first language vocabulary gap that can exist between children (Hart \& Risley, 2003). It is true that most of the vocabularies that we learn are through incidental acquisition (Nagy, 2005), but it does not mean to stop searching for more effective ways of teaching vocabularies explicitly, and evaluating its impact on remediating reading difficulties. The acquisition of a large number of vocabularies is not possible during school time (National Reading Panel, 2000). Hence, extensive in-home interventions could be an appropriate solution to meet this objective. In addition, technologies such as computers could be used to enhance the rate of incidental acquisition of vocabularies.

\subsection{Duration of interventions}

From the analysis of studies that provided the total hour of their interventions, multi-component studies had the longest interventions; this is reasonable because they are focused on multiple reading skills. The phonological awareness comes in the second order with an average of exceeding $28 \mathrm{~h}$. In the third position, phonics and comprehension with more than $18 \mathrm{~h}$, and finally, fluency had an average intervention duration of $12 \mathrm{~h}$ only. It is surprising that fluency interventions had the shortest durations because naturally, it is the skill acquisition that requires a long training time. Fluency needs automaticity, which needs mastery that in turn needs extensive training.

\subsection{Technologies}

From the 32 reading programs discussed in this paper, 29 of them were computer-based. Smartphones and tablets each were used only once. Considering the estimations that there are more than two billion smartphone users and more than one billion tablet users worldwide in 2017 (Statista, n.d.), it is surprising that so few studies are dedicated to evaluating the impact of smartphone and tablet's literacy apps on reading skills. Given the abundant number of available literacy apps in smartphones and tablets, it would be 
25

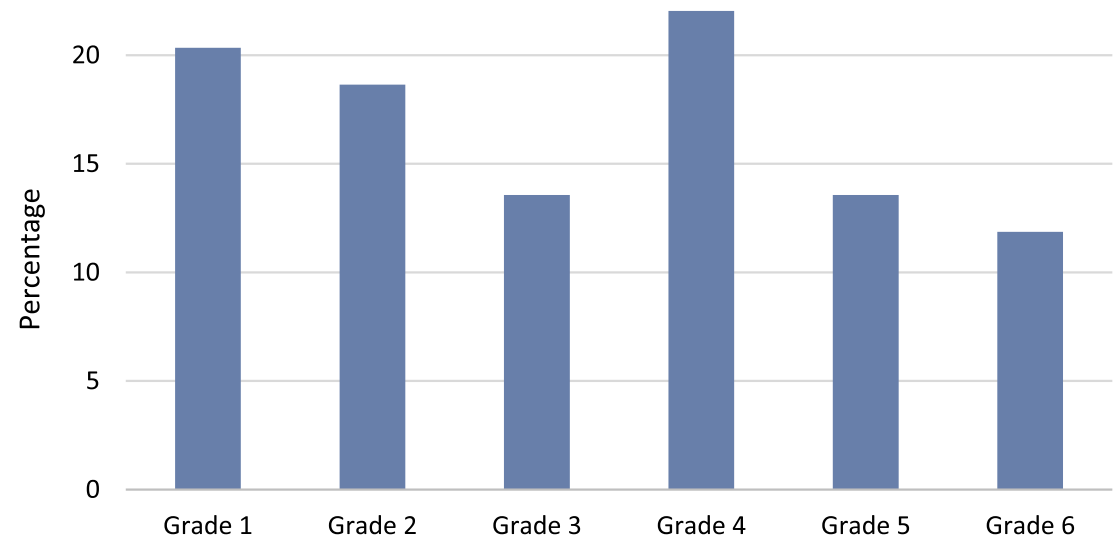

Fig. 5. The percentage share of each grade among the reviewed studies.

beneficial to study their effectiveness and to see which instructional elements have more impact. Moreover, too few papers studied an in-home intervention, which is understandable because tracking the fidelity of the intervention would be harder and less reliable, but given the fact that nowadays the majority of people are connected to the internet, all the use and performance data can be recorded and transferred easily and automatically. Software programs can be created adaptive enough to propose personalized learning sessions to the children, in the absence of their teacher, which can provide an opportunity for learners who do not have sufficient access to qualified tutors.

\subsection{Grade levels}

From the studies that explicitly mentioned the grade level of target groups, as it can be seen in Fig. 5, first, second and fourth graders received more attention (each with near 20 percent), which was predictable. As for the first and second grade, there is a widespread belief that earlier interventions are more effective and it is backed by many scientific studies as well (Lovett et al., 2017; Park, Chaparro, Preciado, \& Cummings, 2015), and also, it is known that fourth grade is the period that the gap between struggling and normal readers will become more distinct, as it is traditionally called the 'fourth grade slump' (Chall \& Jacobs, 2003). It is argued that the reason behind this gap is that in fourth grade, children are no longer learning to read, and instead, they should read to learn other materials. The distribution of interventions over the grades shows that phonological awareness and phonics interventions were used mostly in the early grades. The comprehension interventions were more evenly distributed between the grades. On the other hand, fluency interventions were used mostly in upper elementary grades. However, if the intervention processes were gamified using intuitive interaction techniques that improve motivation and adherence, some fluency interventions could be performed at early grades.

\subsection{Game-based and gamified interventions}

Game-based intervention is an approach where a game such as computer-based narrative games is used to enhance learning. However, in gamified intervention only some game elements are included in non-game context (Deterding, Sicart, Nacke, O'Hara, \& Dixon, 2011). Despite the confirmed improvement of engagement, the benefit of using games for learning might induce side effects such as distraction (Adams, Mayer, Macnamara, Koenig, \& Wainess, 2012). However, the gamification concept has shown to increase the attendance, motivation, and engagement in learning, which are invaluable in developing the reading skills (Gooch, Vasalou, Benton, \& Khaled, 2016; Hong \& Masood, 2014). Hence, gamification of reading interventions could be promising for the future. However, less than one-fourth of the reviewed studies used gamified or game-based programs, which considering the young age of target groups, is less than expected. Most of the gamified or game-based approaches were used in phonological awareness and phonics interventions. The gamification of comprehension and fluency programs is not a common practice; this is due to the nature of reading, which demands high focus and full presence. However, in order to make fluency and comprehension training more appealing, innovative approaches can include game elements such as challenges, rewards and visible cues of progress, to reach a high level of mastery in the taught skills. Moreover, the impact of these extrinsic motivations on the intrinsic motivation of reading should be investigated. However, in most of the studies, the effect of interventions on reading skills are examined, but their role in increasing the motivation to read is overlooked. As it is known, extensive independent reading plays a prominent role in the development of reading skills (Bell, 2001), therefore, increasing the motivation to engage in reading activities can be crucial to future success in reading, especially for struggling readers who find reading a hard and laborious task.

It is important to note that the present review of technology-based interventions was focused on all types of applications using ICT systems, including gamified and game-based approaches. However, not all the reviewed works using gamification or games have 
provided sufficiently detailed description of their reading programs. Hence, it was not possible to distinguish whether they used games or the gamification concept in these reviewed works. For this reason, additional investigations are necessary to specify the appropriate design of gamified/game-based interventions and determine their effect on acquiring reading skills.

\subsection{Languages}

Sixty-four percent of the studies were conducted for English speaking children, and about 10 percent targeted Dutch-speaking children. The other Languages such as French and Spanish represent less than 10 percent each. If the studies are classified into two categories of languages with deeper orthographies (English, French and Chinese) and the ones with shallower orthographies (Finnish, Spanish, German, Swedish and Dutch), the deeper language studies focused more on phonics interventions (28\%), however, studies in transparent languages focused more on fluency interventions (36\%). It has been suggested, that in an opaque language such as English, the biggest reading difficulty is the decoding accuracy, while in transparent languages such as Spanish, the biggest problem of poor readers is reading rate (López-escribano, 2016; López-Escribano, Sánchez-Hípola, Suro Sánchez, \& Leal Carretero, 2014). However, it seems improbable that addressing decoding accuracy of English speaking children would solve all of the reading difficulties, and still, the slow reading rate should be addressed.

\subsection{Study limitations}

This study had some limitations. First, due to the differences in methodologies and excess of variables involved in reviewed papers, it was decided to exclude the meta-analysis procedure, but this study can be used as a precursor to a meta-analysis. In addition, many of the technology-based intervention studies, in their titles do not mention that their interventions are carried out by using a certain technology, which makes it difficult to identify them. Therefore, a more thorough search for these types of studies should result in more papers. Furthermore, in future studies, it will be useful to propose a more in-depth analysis of the characteristics of intervention programs, such as interface design, adaptiveness, affordance and game elements used in the programs. However, unfortunately, many of the studies do not provide sufficient information and enough details about their intervention programs.

\section{Conclusion and future directions}

Due to the utmost importance of reading acquisition and the severe consequences of reading failure, many researchers have been motivated to develop innovative approaches to create more effective reading interventions. This study aimed at presenting a comprehensive overview of the technology-based or technology-assisted reading intervention studies for elementary grades. The purpose of this paper is to provide researchers and designers of reading programs with exhaustive information about the current approaches applied to each reading component and suggest insights by analyzing the reviewed studies with regard to diverse aspects. Since there were similar studies published before 2000, the period from 2000 to 2017 was chosen for this analytical review. In this paper, the reading programs are classified into six categories of phonological awareness, phonics, vocabulary, comprehension, fluency, and multi-component. A general introduction to each of these categories is presented, and the reading programs are summarized by focusing on their content, instructional processes, key features, and the outcome of the interventions. Finally, the paper presents the analysis of the identified pertinent aspects of the reviewed reading intervention studies.

Forty-two studies have been reviewed, resulting in 32 reading programs. Surprisingly, only one study investigated a vocabulary intervention; this indicates that using technology to enhance the first language vocabulary acquisition of early readers is highly overlooked. As mentioned previously, it is challenging to influence the general vocabulary knowledge; this suggests that extensive home-based intervention can be a promising solution. Additionally, the use of non-computer technologies, such as tablets and smartphones are less than what was expected. Furthermore, the average intervention time for fluency was shorter than the duration of other intervention types; this does not satisfy the requirement of long-time training to achieve a high level of fluency. In addition, current fluency approaches lack a holistic view, which addresses different components of fluency at various levels. Moreover, compared to other types of interventions, the gamification of fluency and comprehension programs is not established yet. Additionally, fluency programs were less used in early elementary grades.

The findings of this study suggest that for languages with opaque orthographies such as English, the speed aspect of reading was neglected. Despite the emphasis on teaching phonics for these languages to address precision, still dyslexia is the problem of both accuracy and speed, these aspects should be addressed together in the future studies. Hence, it is recommended to study the efficacy of reading programs that accentuate both the decoding speed and decoding accuracy. Letter recognition automaticity can be trained at first, then word recognition automaticity can be practiced, and later, fluency approaches on the phrase, paragraph, and longer texts can be worked. In addition, instead of making a simple integral digital copy of the existing pedagogical methods used in schools, it is recommended that designers take benefit from the recent advances of information and communication technologies to design innovative methods not available in normal schooling conditions.

In order to develop innovative reading approaches, this analytical review showed that more investigations are necessary. Intelligent self-adaptable systems should be developed to assess the student's skills. These systems should provide individualized interaction modalities and adapt the content of the instruction based on the real-time capture of the user performance. In order to enhance the learning process, gamified multisensory interactive modalities such as spoken speech and tactile interfaces could be integrated to address different human sensory channels. Since it is acquired that emotion can drive motivation, which is crucial for developing reading skills, emotional interaction could also be included to enhance the effectiveness of the reading programs. 
Furthermore, speech recognition was not used at its maximum potential for enhancing the reading acquisition. If advanced integration of speech recognition is made with being sensitive to smaller parts of the language so that it detects not only the pronunciation errors but also the prosody attributes and even the emotional states of the speaker, it would be promising for the creation of intelligent assistive reading systems. Moreover, the technologies of virtual and augmented realities can be used to teach vocabulary, the context relative to each word can be built in a meaningful and realistic way to enhance its retention. Finally, mathematical modeling can be used to maximize the value of the pedagogical content. The mathematical modeling approach could open new research directions to learn from existing mathematical models and to improve their efficacy by experimenting with the elements and attributes that have not been considered previously.

\section{Financial support}

This research has been conducted with the financial support of the European Union through the Beaconing project (Horizon 2020Grant Number 687676). The authors of this paper acknowledge the financial support of the EU and Hands-Free Computing Ltd.

\section{References}

Abraham, L. B. (2008). Computer-mediated glosses in second language reading comprehension and vocabulary learning: A meta-analysis. Computer Assisted Language Learning, 21(3), 199-226. https://doi.org/10.1080/09588220802090246.

Abrami, P., Borohkovski, E., \& Lysenko, L. (2015). The effects of ABRACADABRA on reading outcomes: A meta-analysis of applied field research. Journal of Interactive Learning Research, 26(4), 337-367.

Adams, D. M., Mayer, R. E., Macnamara, A., Koenig, A., \& Wainess, R. (2012). Narrative games for Leaming : Testing the discovery and narrative hypotheses. Journal of Educational Psychology, 104(1), 235.

Andreev, R., Terzieva, V., \& Kademova-Katzarova, P. (2009). An approach to development of personalized e-learning environment for dyslexic pupils' acquisition of reading competence. Proceedings of the international conference on computer systems and technologies and workshop for PhD students in computing - CompSysTech '09: Vol. 1https://doi.org/10.1145/1731740.1731829.

Athanaselis, T., Bakamidis, S., Dologlou, I., Argyriou, E. N., \& Symvonis, A. (2014). Making assistive reading tools user friendly: A new platform for Greek dyslexic students empowered by automatic speech recognition. Multimedia Tools and Applications, 68(3), 681-699. https://doi.org/10.1007/s11042-012-1073-5.

Bell, T. (2001). Extensive reading: Speed and comprehension. The Reading Matrix, 1(1), Retrieved from http://www.readingmatrix.com/articles/bell/article.pdf.

Biemiller, A., \& Slonim, N. (2001). Estimating root word vocabulary growth in normative and advantaged populations: Evidence for a common sequence of vocabulary acquisition. Journal of Educational Psychology, 93(3), 498-520. Retrieved from http://doi.apa.org/journals/edu/93/3/498.pdf.

Bittencourt, T., Savino, J., Fernandes, H., \& Boueri Rebello, L. H. (2016). Mobile device development and its contribution to the treatment of young dyslexic brazilian children. Proceedings of the AHFE 2016 international conference on design for inclusion (pp. 339-349).

Blok, H., Oostdam, R., Otter, M. E., \& Overmaat, M. (2002). Computer-assisted instruction in support of beginning reading instruction: A review. Review of Educational Research, 72(1), 101-130. https://doi.org/10.3102/00346543072001101.

Blomert, L., \& Froyen, D. (2010). Multi-sensory learning and learning to read. International Journal of Psychophysiology, 77(3), 195-204. https://doi.org/10.1016/j. ijpsycho.2010.06.025.

Breznitz, Z., \& Nevat, M. (2004). The reading acceleration program (RAP). Israel: University of Haifa (The Edmond J. Safra Brain Research Center for the Study of Learning Disabilities).

Bus, A. G., \& van IJzendoorn, M. H. (1999). Phonological awareness and early reading: A meta-analysis of experimental training studies. Journal of Educational Psychology, 91(3), 403-414. https://doi.org/10.1037/0022-0663.91.3.403.

Cain, K., \& Oakhill, J. (2006). Profiles of children with specific reading comprehension difficulties. British Journal of Educational Psychology, 76(4), 683-696. https:// doi.org/10.1348/000709905X67610.

Calet, N., Gutiérrez-Palma, N., \& Defior, S. (2016). Effects of fluency training on reading competence in primary school children: The role of prosody. Learning and Instruction. https://doi.org/10.1016/j.learninstruc.2017.04.006.

Cassady, J. C., \& Smith, L. L. (2005). The impact of a structured integrated learning system on first-grade students' reading gains. Reading \& Writing Quarterly, 21(4), 361-376. https://doi.org/10.1080/10573560591002277.

Chall, J. S., \& Jacobs, V. A. (2003). The classic study on poor children's fourth-grade slump. American Educator, 27(1), 14-15.

Chambers, B., Abrami, P., Tucker, B., Slavin, R. E., Madden, N. a., Cheung, A., et al. (2008). Computer-assisted tutoring in success for all: Reading outcomes for first graders. Journal of Research on Educational Effectiveness, 1(2), 120-137. https://doi.org/10.1080/19345740801941357.

Chambers, B., Slavin, R. E., Madden, N. A., Abrami, P., Logan, M. K., \& Gifford, R. (2011). Small-group, computer-assisted tutoring to improve reading outcomes for struggling first and second graders. The Elementary School Journal, 111(4), 625-640. https://doi.org/10.1086/659035.

Chard, D. J., \& Dickson, S. (1999). Phonological awareness: Instructional and assessment guidelines. Intervention in School and Clinic, 34, $261-270$.

Cheung, A. C. K., \& Slavin, R. E. (2011). The effectiveness of education technology for enhancing reading achievement: A meta-analysis. Center for Research and Reform in Education.

Cidrim, L., \& Madeiro, F. (2017). Information and communication technology (ICT) applied to dyslexia: Literature review. Revista CEFAC, 19(1), 99-108. https://doi. org/10.1590/1982-021620171917916.

Clark, C., \& Cunningham, A. E. (2016). Reading enjoyment, behaviour and attitudes in pupils who use accelerated reader. National Literacy Trusthttps://eric.ed.gov/?id= ED570684.

Cognitive Concepts, I. (1998). Earobics auditory development and phonics program step 2. Evanston, IL: Author.

Cohen, W., Hare, A. O., Boyle, J., \& Mccartney, E. (2015). Intervention through acoustically modified speech (Fast ForWord ) in severe mixed receptive-expressive language impairment: Outcomes from a randomized controlled trial. Journal of Speech, Language, and Hearing Research, 48, 715-729 June 2005.

Corbett, A. (2001). Cognitive computer tutors: Solving the two-sigma problem. User modeling 2001 (pp. 137-147). Sonthofen, Germany: Springer, Berlin, Heidelberg. https://doi.org/10.1007/3-540-44566-8_14.

Cunningham, A. E. (2005). Vocabulary growth through independent reading and reading aloud to children. Teaching and learning vocabulary: Bringing research to practice.

Cunningham, A. E., \& Stanovich, K. E. (1997). Early reading acquisition and its relation to reading experience and ability 10 years later. Developmental Psychology, 33(6), 934-945. https://doi.org/10.1037/0012-1649.33.6.934.

Danis, B., Rainville, S., Therrien, M., Tucker, B., \& Abrami, P. (2005). Alphie's Alley early literacy tutoring software. In P. Kommers, \& G. Richards (Eds.). MEDIA 2005world conference on educational multimedia, hypermedia \& telecommunications (pp. 3829-3834). Montreal, Canada: Association for the Advancement of Computing in Education (AACE).

Danon-Boileau, L., \& Barbier, D. (2000). Play-On: Un logiciel d'entraînement à la lecture. Paris: Audivi-Média.

Daud, S. M., \& Abas, H. (2014). "Dyslexia baca" mobile app - the learning ecosystem for dyslexic children. Proceedings - 2013 international conference on advanced computer science applications and technologies (pp. 412-416). ACSAT. 2013 https://doi.org/10.1109/ACSAT.2013.87.

Denckla, M. B., \& Rudel, R. (1974). Rapid “automatized" naming of pictured objects, colors, letters and numbers by normal children. Cortex, 10(2), 186-202. https:// doi.org/10.1016/S0010-9452(74)80009-2. 
Deterding, S., Sicart, M., Nacke, L., O'Hara, K., \& Dixon, D. (2011). Gamification. using game-design elements in non-gaming contexts. Proceedings of the 2011 annual conference extended abstracts on human factors in computing systems - CHI EA '11 (pp. 2425). https://doiorg/10.1145/1979742.1979575.

Easyread (2014). Trainertext. 29 beaumont street. Oxford, OX1 2NP, United Kingdom: DM Education. Retrieved from https://dm-ed.com/info/how-trainertext-works/. Écalle, J. (2004). Timé2: Test d'identification de mots écrits de 6 à 8 ans. EAP, éditions et applications psychologiques.

Ecalle, J., Kleinsz, N., \& Magnan, A. (2013). Computer-assisted learning in young poor readers: The effect of grapho-syllabic training on the development of word reading and reading comprehension. Computers in Human Behavior, 29(4), 1368-1376. https://doi.org/10.1016/j.chb.2013.01.041.

Ecalle, J., Magnan, A., \& Jabouley, D. (2010). Chassymo: Un logiciel d'aide au traitement syllabique [[Chassymo: A software for grapho-syllabic processing]]. Châteauroux: Adeprio Diffusion. Retrieved from www.adeprio.com.

Edwards Santoro, L., \& Bishop, M. J. (2010). Selecting software with caution: An empirical evaluation of popular beginning reading software for children with early literacy difficulties. Computers in the Schools, 27(December 2014), 99-120. https://doi.org/10.1080/07380561003801582.

Ehri, L. C., Nunes, S. R., Stahl, S. A., \& Willows, D. M. (2001a). Systematic phonics instruction helps students learn to read: Evidence from the national reading panel's meta-analysis. Review of Educational Research, 71(3), 393-447. https://doi.org/10.1598/RRQ.36.3.2.

Ehri, L. C., Nunes, S. R., Willows, D. M., Schuster, B. V., Yaghoub-Zadeh, Z., \& Shanahan, T. (2001b). Phonemic awareness instruction helps children learn to read: Evidence from the national reading panel's meta-analysis. Reading Research Quarterly, 36(3), 250-287. https://doi.org/10.1598/RRQ.36.3.2.

Elliott, C. D. (1996). BAS II: British ability Scales (2nd ed.). London: NFER-Nelson.

Erekson, J. (2003). Prosody: The problem of expression in fluency. Annual meeting of the international reading association, orlando, FL.

Fälth, L., Gustafson, S., Tjus, T., Heimann, M., \& Svensson, I. (2013). Computer-assisted interventions targeting reading skills of children with reading disabilities - a longitudinal study. Dyslexia, 19(1), 37-53. https://doi.org/10.1002/dys.1450.

Ferreira, J., Gustafson, S., \& Rönnberg, J. (2003). COMPHOT: Computerized phonological training. Linköping: Institutionen för beteendevetenskap/Institutet för handikappvetenskap. Linköpings universitet.

Gersten, R., Fuchs, L. S., Williams, J. P., \& Baker, S. (2001). Teaching reading comprehension strategies to students with learning disabilities: A review of research. Review of Educational Research, 71(2), 279-320. https://doi.org/10.3102/00346543071002279.

Gooch, D., Vasalou, A., Benton, L., \& Khaled, R. (2016). Using gamification to motivate students with dyslexia. Proceedings of the 2016 CHI conference on human factors in computing systems - CHI '16 (pp. 969-980). New York, New York, USA: ACM Press. https://doi.org/10.1145/2858036.2858231.

Grant, A., Wood, E., Gottardo, A., Evans, M. A., Phillips, L., \& Savage, R. (2012). Assessing the content and quality of commercially available reading software programs: Do they have the fundamental structures to promote the development of early reading skills in children? NHSA Dialog, 15(4), 319-342. https://doi.org/ $10.1080 / 15240754.2012 .725487$.

Greene, F. (1979). Radio reading. Reading Comprehension at Four Linguistic Levels, 104-107.

Gustafson, S., Fälth, L., Svensson, I., Tjus, T., \& Heimann, M. (2011). Effects of three interventions on the reading skills of children with reading disabilities in grade 2. Journal of Learning Disabilities, 44(2), 123-135. https://doi.org/10.1177/0022219410391187.

Gustafson, S., Ferreira, J., \& Rönnberg, J. (2003). DOT: Datorbaserad ortografisk träning. Linköping: Institutionen för beteendevetenskap/Institutet för handikappvetenskap. Linköpings universitet.

Gustafson, S., Ferreira, J., \& Ronnberg, J. (2007). Phonological or orthographic training for children with phonological or orthographic decoding deficits. Dyslexia, 13(3), 211-229. https://doi.org/10.1002/dys.339.

Harris, T. L., \& Hodges, R. E. (1995). The literacy dictionary: The vocabulary of reading and writing. Order department, international reading association, 800 barksdale road, P.O. Box 8139, newark, DE 19714-8139 (book No. 138: \$25 members, \$35 nonmembers). International Reading Association. Retrieved from https://eric.ed.gov/? $\mathrm{id}=\mathrm{ED} 385820$

Hart, B., \& Risley, T. R. (1995). Meaningful differences in the everyday experience of young American children. Paul H Brookes Publishing. Retrieved from http://psycnet. apa.org/psycinfo/1995-98021-000.

Hart, B., \& Risley, T. R. (2003). The early catastrophe: The 30 million word gap by age 3. American Educator, 27(1), 1-6.

Heckelman, R. G. (1969). A neurological-impress method of remedial-reading instruction. Academic Therapy, 4(4), 277-282.

Heimann, M., Lundälv, M., Tjus, T., \& Nelson, K. (2004). Omega-Interactive sentences, a multimedia software for language exploration and play. Göteborg: Topic Data \& Språkbehandling $H B$.

Herron, J. (1995). Read, write, \& type. Freemont, CA: The Learning Company.

Hintikka, S., Aro, M., \& Lyytinen, H. (2005). Computerized training of the correspondences between phonological and orthographic units. Written Language \& Literacy, 8(2), 79-102. https://doi.org/10.1075/wll.8.2.07hin.

Hoff, E. (2003). The specificity of environmental influence: Socioeconomic status affects early vocabulary development via maternal speech. Child Development, 74(5), 1368-1378. https://doi.org/10.1111/1467-8624.00612.

Hong, G. Y., \& Masood, M. (2014). Effects of gamification on lower secondary school students' motivation and engagement. International Journal of Social, Education, Economics and Management Engineering, 8(12), 3750-3757.

Horne, J. K. (2017). Reading comprehension: A computerized intervention with primary-age poor readers. Dyslexia, 23(2), 119-140. https://doi.org/10.1002/dys. 1552.

Hudson, R. F., Pullen, P. C., Lane, H. B., \& Torgesen, J. K. (2009). The complex nature of reading fluency: A multidimensional view. Reading \& Writing Quarterly, 25(1), 4-32. https://doi.org/10.1080/10573560802491208.

Hunt, L. C. (1970). The effect of self-selection, interest, and motivation upon independent, instructional, and frustational levels. The Reading Teacher, 24(2), 146-151. https://doi.org/10.2307/20196461.

Jastak, S., \& Wilkinson, G. (1984). Wide range achievement test-revised. Wilmington, DE: Jastak Associates.

Johnson, R. A., \& Howard, C. A. (2003). The effects of the accelerated reader program on the reading comprehension of pupils in grades three, four and five. The Reading Matrix, 3(3), 30-31.

Kamil, M. L., \& Hiebert, E. H. (2005). Teaching and learning vocabulary: Perspective and persistent issues. Teaching and learning vocabulary: Bringing research to practice (pp. 1-23).

Kendeou, P., Van Den Broek, P., Helder, A., \& Karlsson, J. (2014). A cognitive view of reading comprehension: Implications for reading difficulties. Learning Disabilities Research \& Practice, 29(1), 10-16. https://doi.org/10.1111/ldrp.12025.

Kennedy, M. J., \& Deshler, D. D. (2010). Literacy instruction, technology, and students with learning disabilities: Research we have, research we need. Learning Disability Quarterly, 33(4), 289-298. https://doi.org/10.1177/073194871003300406.

Kim, M. K., Bryant, D. P., Bryant, B. R., \& Park, Y. (2017). A synthesis of interventions for improving oral reading fluency of elementary students with learning disabilities. Preventing School Failure: Alternative Education for Children and Youth, 61(2), 116-125. https://doi.org/10.1080/1045988X.2016.1212321.

Kim, J. S., Capotosto, L., Hartry, A., \& Fitzgerald, R. (2011). Can a mixed-method literacy intervention improve the reading achievement of low-performing elementary school students in an after-school program?: Results from a randomized controlled trial of READ 180 Enterprise. Educational Evaluation and Policy Analysis, 33(2), 183-201. https://doi.org/10.3102/0162373711399148.

Kim, J. S., Samson, J. F., Fitzgerald, R., \& Hartry, A. (2010). A randomized experiment of a mixed-methods literacy intervention for struggling readers in grades 4-6: Effects on word reading efficiency, reading comprehension and vocabulary, and oral reading fluency. Reading and Writing, 23(9), 1109-1129. https://doi.org/10. 1007/s11145-009-9198-2.

Klauda, S. L., \& Guthrie, J. T. (2008). Relationships of three components of reading fluency to reading comprehension. Journal of Educational Psychology, 100(2), 310-321. https://doi.org/10.1037/0022-0663.100.2.310.

Kuder, S. J. (2017). Vocabulary instruction for secondary students with reading disabilities: An updated research review. Learning Disability Quarterly, 40(3), 155-164. https://doi.org/10.1177/0731948717690113.

Kuhn, M. R., Schwanenflugel, P. J., \& Meisinger, E. B. (2010). Aligning theory and assessment of reading fluency: Automaticity, prosody, and definitions of fluency. Reading Research Quarterly, 45(2), 230-251. https://doi.org/10.1598/RRQ.45.2.4. 
Kyle, F., Kujala, J., Richardson, U., Lyytinen, H., \& Goswami, U. (2013). Assessing the effectiveness of two theoretically motivated computer-assisted reading interventions in the United Kingdom: GG rime and GG phoneme. Reading Research Quarterly, 48(1), 61-76. https://doi.org/10.1002/rrq.038.

LaBerge, D., \& Samuels, S. J. (1974). Toward a theory of automatic information processing in reading. Cognitive Psychology, 6(2), 293-323. https://doi.org/10.1016/ 0010-0285(74)90015-2.

Lexia Learning Systems (2001). Phonics based reading and strategies for older students. Lincoln, MA: Lexia Learning Systems, Inc.

Lee, J., \& Yoon, S. Y. (2017). The effects of repeated reading on reading fluency for students with reading disabilities. Journal of Learning Disabilities, 50(2), 213-224. https://doi.org/10.1177/0022219415605194.

Lindamood, P. C., Lindamood, P., \& Truch, S. (1998). The Lindamood phoneme sequencing program for reading, spelling and speech: The LIPS Program. Pro-Ed.

Lin, C. Y., Yu, W. J., Chen, W. J., Huang, C. W., \& Lin, C. C. (2016). The effect of literacy learning via mobile augmented reality for the students with ADHD and reading disabilities. International conference on universal access in human-computer interaction (pp. 103-111). Cham: Springer. https://doi.org/10.1007/978-3-319-40238$3 \_11$.

López-escribano, C. (2016). Training reading fluency and comprehension of Spanish children with dyslexia. Reading fluency (pp. 141-161). Springer International Publishing. https://doi.org/10.1007/978-3-319-30478-6_9.

López-Escribano, C., Sánchez-Hípola, P., Suro Sánchez, J., \& Leal Carretero, F. (2014). Comparative analysis of rapid automatized naming studies in Spanish and reading acquisition and reading difficulties. Universitas Psychologica, 13(2), 757-769.

Lovett, M. W., Frijters, J. C., Wolf, M., Steinbach, K. A., Sevcik, R. A., \& Morris, R. D. (2017). Early intervention for children at risk for reading disabilities: The impact of grade at intervention and individual differences on intervention outcomes. Journal of Educational Psychology, 109(7), 889-914. https://doi.org/10.1037/ edu0000181.

Lucid Research (2010). Comprehension booster. 3 spencer street, beverley, east yorkshire. HU17 9EG. U.K.: Lucid Research Limited.

Lyytinen, H., Erskine, J., Aro, M., \& Richardson, U. (2008). Reading and reading disorders. Blackwell handbook of language development. https://doi.org/10.1002/ 9780470757833.ch22.

Lyytinen, H., Erskine, J., Kujala, J., Ojanen, E., \& Richardson, U. (2009). In search of a science-based application: A learning tool for reading acquisition. Scandinavian Journal of Psychology, 50(6), 668-675. https://doi.org/10.1111/j.1467-9450.2009.00791.x.

Lyytinen, H., Ronimus, M., Alanko, A., Poikkeus, A.-M., \& Taanila, M. (2007). Early identification of dyslexia and the use of computer game-based practice to support reading acquisition. Nordic Psychology, 59(2), 109-126. https://doi.org/10.1027/1901-2276.59.2.109.

MacArthur, C. A., Ferretti, R. P., Okolo, C. M., \& Cavalier, A. R. (2001). Technology applications for students with literacy problems: A critical review. The Elementary School Journal, 101(3), 273-301. https://doi.org/10.1086/499669.

Macaruso, P., Hook, P. E., \& McCabe, R. (2006). The efficacy of computer-based supplementary phonics programs for advancing reading skills in at-risk elementary students. Journal of Research in Reading, 29(2), 162-172. https://doi.org/10.1111/j.1467-9817.2006.00282.x.

Macginitie, W. H., Macginitie, R. K., Cooter, R. B., Cooter, J., \& Curry, S. (1989). Assessment: Gates-Macginitie reading tests, third edition. The Reading Teacher, 43(3), 256-258. Retrieved from http://www.jstor.org/stable/20200351.

MacGinitie, W. H., MacGinitie, R. K., Maria, K., Dreyer, L. G., \& Hughes, K. E. (2000). Gates-MacGinitie reading test (GMRT) (4th ed.). Itasca, IL: Riverside Publishing.

Madden, N. A., \& Slavin, R. E. (2017). Evaluations of technology-assisted small-group tutoring for struggling readers. Reading \& Writing Quarterly, 1-8https://doi.org/ 10.1080/10573569.2016.1255577.

Magnan, A., Ecalle, J., Veuillet, E., \& Collet, L. (2004). The effects of an audio-visual training program in dyslexic children. Dyslexia, 10(2), 131-140. https://doi.org/ 10.1002/dys.270.

Malouf, D. B. (1988). The effect of instructional computer games on continuing student motivation. The Journal of Special Education, 21(4), 27-38. https://doi.org/10. $1177 / 002246698802100406$.

Mayer, R. E. (1996). Learning strategies for making sense out of expository Text. The SOI Model for Guiding Three Cognitive Processes in Knowledge Construction, 8(4), $357-371$.

Mayer, R. E., \& Moreno, R. (2010). Nine ways to reduce cognitive load in multimedia learning. Educational Psychologist, 38(1), 43-52. https://doi.org/10.1207/ S15326985EP3801.

Mckeown, M. G., Beck, I. L., \& Blake, R. G. K. (2009). Rethinking reading comprehension. Reading Research Quarterly, 44(3), 218-253. https://doi.org/dx.doi.org/10. 1598/RRQ.44.3.1.

Melby-Lervåg, M., Lyster, S.-A., \& Hulme, C. (2012). Phonological skills and their role in learning to read: A meta-analytic review. Psychological Bulletin, 138(2), 322-352. https://doi.org/10.1037/a0026744.

Mesmer, H. A. E., \& Griffith, P. L. (2005). Everybody's selling it-but just what is explicit, systematic phonics instruction? The Reading Teacher, 59(4), 366-376. https:// doi.org/10.1598/RT.59.4.6.

Messer, D., \& Nash, G. (2017). An evaluation of the effectiveness of a computer-assisted reading intervention. Journal of Research in Reading, 1-19. https://doi.org/10. 1111/1467-9817.12107.

MindPlay (2012). MindPlay virtual reading Coach. 4400 E. Broadway blvd., suite 400 tucson, AZ 85711: Mindplay: Research-based educational software for reading instruction. Retrieved from http://mindplay.com/student-programs/virtual-reading-coach/.

Moser, G. P. (2012). 8 Great word patterns. Orem, UT: Bugbrained, LLC.

Moser, G. P., Morrison, T. G., \& Wilcox, B. (2017). Supporting fourth-grade students' word identification using application software. Reading Psychology, 38(4), 349-368. https://doi.org/10.1080/02702711.2016.1278414.

Nagler, T., Korinth, S. P., Linkersdörfer, J., Lonnemann, J., Rump, B., Hasselhorn, M., et al. (2015). Text-fading based training leads to transfer effects on children's sentence reading fluency. Frontiers in Psychology, 6, 1-8. https://doi.org/10.3389/fpsyg.2015.00119.

Nagy, W. (2005). Why vocabulary instruction needs to be long-term and comprehensive. Teaching and learning vocabulary: Bringing research to practice (pp. 27-44).

Nation, K. (2005). Children's reading comprehension difficulties. The Science of Reading: The Hand, 248-265. https://doi.org/10.1002/9780470757642.ch14.

National Assessment of Educational Progress (2015). The nation's report card: 2015 mathematics and reading assessments. Washington, DC.

National Governors Association (2010). Common core state standards for English language arts \& literacy in history/social studies, science, and technical subjects.

National Reading Panel (2000). Teaching children to read: An evidence-based assessment of the scientific research literature on reading and its implications for reading instruction. NIH Publication. No. 00-4769 https://doi.org/10.1002/ppul.1950070418.

Neuman, S. B., \& Dwyer, J. (2009). Missing in action: Vocabulary instruction in pre-K. The Reading Teacher, 62(5), 384-392. https://doi.org/10.1598/rt.62.5.2.

Nicolson, R., Fawcett, A., \& Nicolson, M. (2000). Evaluation of a computer-based reading intervention in infant and junior schools. Journal of Research in Reading, 23(2), 194-209. https://doi.org/10.1111/1467-9817.00114.

Niedo, J., Lee, Y., Breznitz, Z., \& Berninger, V. W. (2014). Computerized silent reading rate and strategy instruction for fourth graders at risk in silent reading rate. Learning Disability Quarterly, 37(2), 100-110. https://doi.org/10.1177/0731948713507263.

Nunnery, J. A., Ross, S. M., \& McDonald, A. (2006). A randomized experimental evaluation of the impact of accelerated reader/reading renaissance implementation on reading achievement in grades 3 to 6. Journal of Education for Students Placed at Risk, 11(1), 1-18. https://doi.org/10.1207/s15327671espr1101_1.

Ojanen, E., Ronimus, M., Ahonen, T., Chansa-Kabali, T., February, P., Jere-Folotiya, J., et al. (2015). GraphoGame-A catalyst for multi-level promotion of literacy in diverse contexts. Frontiers in Psychology, 6(671), 1-13. https://doi.org/10.3389/fpsyg.2015.00671.

Ouellette, G. P. (2006). What's meaning got to do with it: The role of vocabulary in word reading and reading comprehension. Journal of Educational Psychology, 98(3), 554-566. https://doi.org/10.1037/0022-0663.98.3.554.

Paige, D. D. (2011). Testing the acceleration hypothesis: Fluency outcomes utilizing still-versus accelerated-text in sixth-grade students with reading disabilities. Literacy Research and Instruction, 50(4), 294-312. https://doi.org/10.1080/19388071.2010.518661.

Papastergiou, M. (2009). Digital Game-Based Learning in high school Computer Science education: Impact on educational effectiveness and student motivation. Computers \& Education, 52(1), 1-12. https://doi.org/10.1016/j.compedu.2008.06.004.

Park, Y., Chaparro, E. A., Preciado, J., \& Cummings, K. D. (2015). Is earlier better? Mastery of reading fluency in early schooling. Early Education \& Development, 26(8), 
1187-1209. https://doi.org/10.1080/10409289.2015.1015855.

Patel, R., Kember, H., \& Natale, S. (2014). Feasibility of augmenting text with visual prosodic cues to enhance oral reading. Speech Communication, 65, 109-118. https://doi.org/10.1016/j.specom.2014.07.002.

Patel, R., \& McNab, C. (2011). Displaying prosodic text to enhance expressive oral reading. Speech Communication, 53(3), 431-441. https://doi.org/10.1016/j.specom. 2010.11.007.

Pennington, B. F., \& Lefly, D. L. (2012). Early reading development in children at family risk for dyslexia. Child Development, 72(3), 816-833.

Peterson, R. L., \& Pennington, B. F. (2015). Developmental dyslexia. Annual Review of Clinical Psychology, 11(1), 283-307. https://doi.org/10.1146/annurev-clinpsy032814-112842.

Pokorni, J. L., Worthington, C. K., \& Jamison, P. J. (2004). Phonological awareness intervention: Comparison of fast ForWord, Earobics, and LiPS. The Journal of Educational Research, 97(3), 147-158. https://doi.org/10.3200/JOER.97.3.147-158.

Ponce, H. R., López, M. J., \& Mayer, R. E. (2012). Instructional effectiveness of a computer-supported program for teaching reading comprehension strategies. Computers \& Education, 59(4), 1170-1183. https://doi.org/10.1016/j.compedu.2012.05.013.

Potocki, A., Ecalle, J., \& Magnan, A. (2013). Effects of computer-assisted comprehension training in less skilled comprehenders in second grade: A one-year follow-up study. Computers \& Education, 63, 131-140. https://doi.org/10.1016/j.compedu.2012.12.011.

Ramus, F. (2003). Developmental dyslexia: Specific phonological deficit or general sensorimotor dysfunction? Current Opinion in Neurobiology, 13(2), 212-218. https:// doi.org/10.1016/S0959-4388(03)00035-7.

Rasinski, T. (2006). Reading fluency instruction: Moving beyond accuracy, automaticity and prosody. The Reading Teacher, 59(7), 704-706. https://doi.org/10.1598/ RT.59.7.10.

Rello, L., Bayarri, C., \& Gorriz, A. (2012). What is wrong with this word? dyseggxia:a game for children with dyslexia. 14th international ACM SIGACCESS conference on computers and accessibility, ASSETS 2012 (pp. 219-220). ACM. https://doi.org/10.1145/2384916.2384962.

Rello, L., Bayarri, C., \& Gòrriz, A. (2013). Dyslexia exercises on my tablet are more fun. Proceedings of the 10th international cross-disciplinary conference on web accessibility - W4A '13 (pp. 20). ACM. https://doi.org/10.1145/2461121.2461148.

Renaissance Learning (1986). Accelerated reader, Vol. 800, P.O. Box 8036, Wisconsin Rapids, WI 54495: Renaissance Learning338-4204.

Revy, P. (2005). Oppositions Phonologiques [[Software Phonological Oppositions]]. Lyon: Gerip. Retrieved from www.gerip.com.

Ricci, K. E., Salas, E., \& Cannon-bowers, J. A. (1996). Do computer-based games facilitate knowledge acquisition and Retention? Military Psychology, 8(4), 295-307. https://doi.org/10.1207/s15327876mp0804_3.

Rosas, R., Escobar, J.-P., Ramírez, M.-P., Meneses, A., \& Guajardo, A. (2017). Impact of a computer-based intervention in Chilean children at risk of manifesting reading difficulties/Impacto de una intervención basada en ordenador en niños chilenos con riesgo de manifestar dificultades lectoras. Infancia y Aprendizaje, 40(1), 158-188. https://doi.org/10.1080/02103702.2016.1263451.

Saine, N. L., Lerkkanen, M. K., Ahonen, T., Tolvanen, A., \& Lyytinen, H. (2011). Computer-assisted remedial reading intervention for school beginners at risk for reading disability. Child Development, 82(3), 1013-1028. https://doi.org/10.1111/j.1467-8624.2011.01580.x.

Samuels, S. J. (1979). The method of repeated readings. The Reading Teacher, 32(4), 403-408. https://doi.org/10.2307/20194790.

Savage, R. S., Abrami, P., Hipps, G., \& Deault, L. (2009). A randomized controlled trial study of the ABRACADABRA reading intervention program in grade 1. Journal of Educational Psychology, 101(3), 590-604. https://doi.org/10.1037/a0014700.

Savage, R. S., Erten, O., Abrami, P., Hipps, G., Comaskey, E., \& van Lierop, D. (2010). ABRACADABRA in the hands of teachers: The effectiveness of a web-based literacy intervention in grade 1 language arts programs. Computers \& Education, 55(2), 911-922. https://doi.org/10.1016/j.compedu.2010.04.002.

Scarborough, H. S. (1991). Antecedents to reading disability: Preschool language development and literacy experiences of children from dyslexic families. Reading and Writing, 3(3-4), 219-233. https://doi.org/10.1007/BF00354959.

Scarborough, H. S., Neuman, S. B., \& Dickinson, D. (2001). Connecting early language and literacy to later reading (dis) abilities: Evidence, theory, and practice. Approaching difficulties in literacy development: Assessment, pedagogy and programmes (pp. 97-110). .

Schneider, D., Chambers, A., Mather, N., Bauschatz, R., Bauer, M., \& Doan, L. (2016). The effects of an ICT-based reading intervention on students' achievement in grade two. Reading Psychology, 37(5), 793-831. https://doi.org/10.1080/02702711.2015.1111963.

Schrank, F. A., Mather, N., \& McGrew, K. S. (2014). Woodcock-Johnson IV tests of achievement. Rolling Meadows, IL: Riverside.

Scientific Learning Corporation (1997). Fast ForWord. Oakland, CA: Scientific Learning Corporation.

Scior, K. (2011). Public awareness, attitudes and beliefs regarding intellectual disability: A systematic review. Research in Developmental Disabilities, 32(6), 2164-2182. https://doi.org/10.1016/j.ridd.2011.07.005.

Sénéchal, M., \& Ouellette, G. (2006). The misunderstood giant: On the predictive role of early vocabulary to future reading. Handbook of early literacy research: Vol. 2, (pp. 173-182).

Shannon, L. C., Styers, M. K., Wilkerson, S. B., \& Peery, E. (2015). Computer-assisted learning in elementary reading: A randomized control trial. Computers in the Schools, 32(1), 20-34. https://doi.org/10.1080/07380569.2014.969159.

Snellings, P., van der Leij, A., de Jong, P. F., \& Blok, H. (2015). Enhancing the reading fluency and comprehension of children with reading disabilities in an orthographically transparent language. Journal of Learning Disabilities, 42(4), 291-305. https://doi.org/10.1177/0022219408331038.

Snowling, M. J. (2001). From language to reading and dyslexia. Dyslexia, 7(1), 37-46. https://doi.org/10.1002/dys.185.

Stahl, S. A. (1992). Saying the "p" word: Nine guidelines for exemplary phonics instruction. The Reading Teacher, 45(8), 618-625. Retrieved from www.jstor.org/ stable/20200939.

Stahl, S. A. (2005). Four problems with teaching word meanings. Teaching and learning vocabulary: Bringing research to practice (pp. 95-114). .

Statista. (n.d.). Number of smartphone users worldwide from 2014 to 2020 (in billions). Retrieved October 10, 2017, from https://www.statista.com/statistics/ 330695/number-of-smartphone-users-worldwide/.

Steenbeek-Planting, E. G., Boot, M., de Boer, J. C., Van de Ven, M., Swart, N. M., \& van der Hout, D. (2013a). Evidence-based psycholinguistic principles to remediate reading problems applied in the playful app letterprins: A perspective of quality of healthcare on learning to read. Games for healthWiesbaden: Springer Fachmedien Wiesbadenhttps://doi.org/10.1007/978-3-658-02897-8_22.

Steenbeek-Planting, E. G., van Bon, W. H. J., \& Schreuder, R. (2012). Improving word reading speed: Individual differences interact with a training focus on successes or failures. Reading and Writing, 25(9), 2061-2089. https://doi.org/10.1007/s11145-011-9342-7.

Steenbeek-Planting, E. G., Van Bon, W. H. J., \& Schreuder, R. (2013b). Improving the reading of bisyllabic words that involve context-sensitive spelling rules: Focus on successes or on failures? Reading and Writing, 26(9), 1437-1458. https://doi.org/10.1007/s11145-012-9425-0.

Stevens, E. a., Walker, M. a., \& Vaughn, S. (2016). The effects of reading fluency interventions on the reading fluency and reading comprehension performance of elementary students with learning disabilities: A synthesis of the research from 2001 to 2014. Journal of Learning Disabilities, 1-15. https://doi.org/10.1177/ 0022219416638028.

Strong, G. K., Torgerson, C. J., Torgerson, D., \& Hulme, C. (2011). A systematic meta-analytic review of evidence for the effectiveness of the "Fast ForWord" language intervention program. The Journal of Child Psychology and Psychiatry and Allied Disciplines, 52(3), 224-235. https://doi.org/10.1111/j.1469-7610.2010.02329.x.

Sung, Y. T., Chang, K. E., \& Huang, J. S. (2008). Improving children's reading comprehension and use of strategies through computer-based strategy training. Computers in Human Behavior, 24(4), 1552-1571. https://doi.org/10.1016/j.chb.2007.05.009.

Topping, K. (1987). Paired reading: A powerful technique for parent use. The Reading Teacher, 40(7), 608-614. https://doi.org/10.2307/20199562.

Torgerson, C. J., Brooks, G., \& Hall, J. (2006). A systematic review of the research literature on the use of phonics in the teaching of reading and spelling. Nottingham: DfES Publications.

Torgesen, J. K., Rashotte, C. A., \& Wagner, R. K. (1999). TOWRE: Test of word reading efficiency. Austin, TX: Pro-ed.

Torgesen, J. K., Wagner, R. K., Rashotte, C. A., Herron, J., \& Lindamood, P. (2010). Computer-assisted instruction to prevent early reading difficulties in students at risk for dyslexia: Outcomes from two instructional approaches. Annals of Dyslexia, 60(1), 40-56. https://doi.org/10.1007/s11881-009-0032-y.

Toste, J. R., \& Ciullo, S. (2017). Reading and writing instruction in the upper elementary grades. Intervention in School and Clinic, 52(5), 259-261. https://doi.org/10. 
$1177 / 1053451216676835$

Treiman, R., \& Zukowski, A. (1991). Levels of phonological awareness. Phonological processes in literacy: A tribute to isabelle Y.

Tzouveli, P., Schmidt, A., Schneider, M., Symvonis, A., \& Kollias, S. (2008). Adaptive reading assistance for the inclusion of students with dyslexia: The AGENT-DYSL approach. The 8th IEEE international conference on advanced learning technologies, ICALT 2008 (pp. 167-171). IEEE. https://doi.org/10.1109/ICALT.2008.236.

Valencia, S. (1990). A portfolio approach to classroom reading assessment: The whys, whats, and hows. The Reading Teacher, 43(4), 338-340. https://doi.org/Article.

Van Den Bosch, K., van Bon, W. H. J., \& Schreuder, R. (1995). Poor readers' decoding skills: Effects of training with limited exposure duration. Reading Research Quarterly, 30(1), 110-125. https://doi.org/Doi 10.2307/747747.

Vaughn, S., Chard, D. J., Bryant, D. P., Coleman, M., Tyler, B., \& Linan-thompson, S. (1999). Fluency and comprehension interventions for third-grade students. Remedial and Special Education, 21(6), 325-335. https://doi.org/10.1177/074193250002100602.

Vaughn, S., Linan-thompson, S., Kouzekanani, K., Bryant, D. P., Dickson, S., \& Blozis, S. A. (2003). Reading instruction grouping for students with reading difficulties. Remedial and Special Education, 24(5), 301-315. https://doi.org/10.1177/07419325030240050501.

Vellutino, F. R., Fletcher, J. M., Snowling, M. J., \& Scanlon, D. M. (2004). Specific reading disability (dyslexia): What have we learned in the past four decades? The Journal of Child Psychology and Psychiatry and Allied Disciplines, 45(1), 2-40. https://doi.org/10.1046/j.0021-9630.2003.00305.x.

van de Ven, M., de Leeuw, L., van Weerdenburg, M., \& Steenbeek-Planting, E. G. (2017). Early reading intervention by means of a multicomponent reading game. Journal of Computer Assisted Learning, 33(4), 320-333. https://doi.org/10.1111/jcal.12181.

Wagner, R., Torgesen, J., \& Rashotte, C. (1999). Comprehensive test of phonological processes (CTOPP). Austin, TX: Pro-.

Wiederholt, J. L., \& Bryant, B. R. (1992). Gray oral reading tests: GORT-3. Austin, TX: Pro-.

Wiederholt, J. L., \& Bryant, B. R. (2001). Gray oral reading test-(GORT-4). Austin, TX: Pro-Ed.

Williams, K. T. (2001). Group reading assessment and diagnostic evaluation: Teacher's scoring \& interpretive manual. Circle Pines, MN: American Guidance Service.

Williams, T. C., \& Zahed, H. (1996). Computer-based training versus traditional lecture: Effect on learning and retention. Journal of Business and Psychology, 11(2), 297-310. https://doi.org/10.1007/BF02193865.

Wise, B. W., Ring, J., \& Olson, R. K. (2000). Individual differences in gains from computer-assisted remedial reading. Journal of Experimental Child Psychology, 77(3), 197-235. https://doi.org/10.1006/jecp.1999.2559.

Wolf, M., \& Denckla, M. B. (2005). RAN/RAS: Rapid automatized naming and rapid alternating stimulus tests. Austin, TX: Pro-ed.

Wolf, M., \& Katzir-Cohen, T. (2001). Reading fluency and its intervention. Scientific Studies of Reading, 5(3), 211-239. https://doi.org/10.1207/S1532799XSSR0503.

Woodcock, R. W., McGrew, K. S., \& Mather, N. (2001). Woodcock-Johnson tests of achievement. Itasca, IL: Riverside Publishing.

Wyse, D., \& Goswami, U. (2008). Synthetic phonics and the teaching of reading. British Educational Research Journal, 34(6), 691-710. https://doi.org/10.1080/ 01411920802268912.

Xin, J. F., \& Rieth, H. (2001). Video-assisted vocabulary instruction for elementary school students with learning disabilities. Information Technology in Childhood Education Annual, 1, 87-103. 